ANUARIo DE ESTUdios MEdiEvales (AEM)

36/1, enero-junio de 2006

pp. $201-240$

ISSN 0066-5061

\title{
«SEGUIR LES VESTÍGIES DELS ANTECESSORS». LLINATGE, REIALESA I HISTORIOGRAFIA A CATALUNYA DES DE RAMON BERENGUER IV A PERE II (1131-1285) ${ }^{1}$
}

STEFANO MARIA CiNGOLANI

Resum: En aquest estudi s'estudia com es forma la consciència dinàstica en els comtes de Barcelona i quines evolucions admet un cop assumida la corona reial d'Aragó. L'anàlisi de les fonts historiogràfiques, poètiques i documentals permet resseguir alguns moments d'aquesta evolució ideològica, i de com se centra al voltant de les idees de noblesa moral i de imitació dels avantpassats. Per la seva banda també la historiografia és condicionada, en els seus plantejaments, per a l'evolució del sentiment dinàstic i de la concepció de la reialesa. Finalment, s'examinen els monuments escrits que són els fonaments de la consciència dinàstica.

Paraules clau: Poder; Reialesa; Alfons I; Historiografia; Corona d'Aragó.

\begin{abstract}
This paper aim to point out the evolution of the dinastic selfconsciousness of the counts of Barcelona and which evolutions it admits once the counts take up the royal crown of Aragon. The study of the historiographical, poetical and documentary sources make possible to appreciate some steps of this ideological evolution, and to observe how it is pivoted to the ideas of moral nobility and the imitation of the ancestors. In consequence, also historiography is conditioned, in its aims, by the evolution of the dinastic consciousness and the regality's conceptions. Finally, it consider the written monuments of the dinastic consciusness.
\end{abstract}

Keywords: Power; Kingsship; Alfons I; Historiography; Crown of Aragon.

${ }^{1}$ Vull agrair a Josep Maria Salrach la lectura atenta i generosa en observacions d'aquest article, això que m'ha dit m'ha ajudat molt. Evidentment la responsabilitat de l'escrit és totalment meva. 


\section{SUMARI}

1. Ramon Berenguer IV i la consciència del llinatge 2. Bernat Desclot i la reialesa 3. Conceptes de noblesa: noblesa per la sang o per la virtut 4. Imitació dels avantpassats com a ideologia reial 5. Llinatge, poder, historiografia i mites dels orígens 6 . Historiografia i legitimitat 7 . Retòrica curial i teoria política.

\section{RAMON BERENGUER IV I LA CONSCIÈNCIA DEL LLINATGE}

Desclot narra, al començament de la seva crònica, l'episodi força llegendari de quan l'exiliat Gran Senescal Guillem Ramon retorna a prop del comte de Barcelona, senyor seu, amb l'oferta dels aragonesos que es casi amb l'hereva al regne'

Sènyer, els rics hòmens d'Aragó m'an tramès a vós per so cor vos tenen per lo pus honrat comte e el pus prous qui sia e·l món e cel qui més ha conquès; e presenten-vos lo regisme d'Aragó e que prenats la donzela per muler, de qui és lo regisme; e éls tots preguen-vos que siats lur senyor e lur rey (cap. 3).

El comte Ramon Berenguer IV, que per Desclot és l'indefinit Bon Comte $^{3}$, barreja d'ell, del seu pare i de la llegenda, respon amb les següents paraules:

Certes (...) assí ha bel present e tal qui no fa a rrefusar. E yo (...) reeb la donzela e el regisme en aytal manera: que, aytant con viva, no vul éser apelat rey; que yo són ara $\cdot \mathrm{I} \cdot$ dels melors chomtes del món, e si era apelat rey, no seria gens dels majors.

Amb aquesta afirmació Ramon Berenguer, i el mateix Desclot, expressen un profund orgull pel valor de la nissaga comtal, pel seu alt linyatge. Em sembla interessant notar com Desclot, que escriu aquest capítol entre 1286 i 1288, a un segle i mig de distància de la unió de les dues nissagues, i quan regna Alfons II de Catalunya, III d'Aragó, cinquè rei 1951

${ }^{2}$ Bernat Desclot, Crònica, ed. Miquel Coll i Alentorn, 5 vols., Barcelona, ENC, 1949-

${ }^{3}$ Vg. Stefano Maria CINGOLANI, Historiografia, propaganda i comunicació al segle XIII: Bernat Desclot i les dues redaccions de la seva Crònica, Barcelona, IEC, 2005, caps. 2 i 4, vegi's en general per qualsevol informació relacionada amb Desclot. 
d'Aragó del casal de Barcelona, encara expressi la idea de la superioritat, del punt de vista del llinatge, de la sang comtal barcelonesa sobre la reial aragonesa. Tampoc no s'ha de menystenir, del punt de vista retòric, el fet que a la crònica de Desclot ni Alfons I d'Aragó, ni Raimir II ni Peronella no són nomenats, sinó que són assenyalats amb un genèric 'el rei', 'la infanta', etc.

És possible, com sugeria Ramon d'Abadal ${ }^{4}$, que, com a idea, la de la superioritat comtal sobre la reial és un invent del propi historiador, ja que, evidentment, no tenim proves explícites i directes que Ramon Berenguer IV compartís semblant ideologia, encara menys que hagués pronunciat tals paraules. Tanmateix, em sembla creïble pensar que Desclot, en bona mesura, rebés aquesta concepció de la mateixa ideologia comtal i reial. Al meu entendre, podem creure que la idea que Desclot presta al comte es correspon, si fa no fa, amb això que podia pensar el mateix Ramon Berenguer IV. Estic convençut que Ramon Berenguer IV considerava més important l'honor familiar de Barcelona que l'adquirit d'Aragó. Els elements que es poden adduir per confirmar aquesta hipòtesi no són ni gaire ni concloents, tot i així no són pas per menystenir.

Considerem, d'entrada, el significat de la tria dels noms dels seus fills. No és el cas d'entretenir-se teòricament, al ser fet prou conegut, sobre el valor polític de l'elecció dels noms dels fills del rei, la seva importància respecte al sentiment dinàstic i a la simbologia del poder reial, amb els necessaris equilibris entre les tradicions de la pròpia nissaga $i$ les exigències de les noves famílies entroncades per via de matrimoni. És el primogènit qui porta el nom significatiu que assenyala la continuïtat del llinatge, o que marca l'entrada en un de més important, mentre els altres fills poden recollir-ne dels llinatges amb els quals s'ha estret un lligam de parentiu. Ara bé, el primer fill de Ramon Berenguer s'havia de dir exactament Ramon Berenguer, com ell i els seus antecessors, i només el secundogènit transmetia el nom aragonès de Pere, tal com testimonia l'adveració sacramental del seu testament:

Dimisit filio suo maiori Raymundo omnem suum onorem de Aragone et Barchinona (...) et dimisit alii filio suo Petro $(\ldots)^{5}$.

${ }^{4}$ Ramon d'ABADAL, Pere el Cerimoniós i els inicis de la decadència política de Catalunya, Barcelona, 1987, p. 66 ( $1^{\text {a }}$ ed. castellana $1966,1^{\text {a }}$ ed. catalana 1972).

${ }^{5}$ Antoni Udina I ABELLó, Els testaments dels comtes de Barcelona i dels reis de la Corona d'Aragó. De Guifré Borrell a Joan II, Barcelona, 2001, p. 104. 
És evident, doncs, com pel comte de Barcelona, ara també príncep d'Aragó, el nou domini adquirit, amb la corona reial que comportava, no era sentit com a superior, en quant a valor i prestigi, al títol comtal tradicional del seu llinatge. El regne d'Aragó, respecte a altres honores adquirits per via matrimonial, com la Provença per exemple -territori del qual es pot disposar per dotar filles o fills fadristerns-, és més valorat puix que queda en el nucli dels dominis del primogènit. Tot i així, no és considerat prou més important, d'un punt de vista polític, com perquè la seva adquisició aconselli canviar la nominació tradicional dels fills del comte de Barcelona, a partir d'ara comterei.

Però, un cop mort el comte, la reina Peronella va arreglar les coses, seguint el seu de sentit dinàstic, i serà el que serà vigent després d'ella: el primogènit va adquirir el nom familiar, i reial, d'Alfons, I de Catalunya i II d'Aragó, i el secundogènit és va adequar a la seva dignitat de comte de Provença, assumint-ne el nom ja dinàstic de Ramon Berenguer, el III:

Dono et laudo et concedo tibi, dilecti filio meo Ildefonso, regi Aragonensi et comiti Barchinonensi, qui in testamento eiusdem viri mei vocaris Raimundus ${ }^{6}$.

Una situació semblant i oposada la trobem amb la nominació del rei Jaume I, on a la correcta ideologia dinàstica del rei Pere I s'oposa la voluntat volgudament antidinàstica de la seva mare, la reina Maria, la qual, amb la elecció d'aquest nou nom, aparentment rebutja el llinatge de la branca aragonesa del seu fill, i també de les seves pròpies ascendències, en tant que senyors de Montpellier, amb el nom dinàstic de Guillem, o dels Comnens, avantpassats pel costat matern. És possible, també, que la qüestió del nom sigui una indirecta censura a la figura de Pere I.

El rei Jaume explica que el seu nom va ser escollit per la reina Maria la qual va fer encendre dotze ciris, un amb el nom de cada apòstol, les sortes apostolorum, i el que va durar més va ser el de Sant Jaume ${ }^{7}$. És d'aquesta manera que es va escollir un nom absolutament nou, tant al llinatge dels comtes de Barcelona com al dels reis d'Aragó, i també nou respecte a totes les

${ }^{6}$ Liber Feudorum Maior, ed. Francisco MIQUEL, 2 vols., Barcelona, 1945, doc. 17.

${ }^{7}$ Aquesta és la versió que donen el Libre dels fets, ed. Jordi BRUGUERA, 2 vols., Barcelona, ENC, 1991, cap. 5, i les Gesta Comitum Barchinonensium IV -per aquestes vg. la nota 21. 
nissagues amb les quals, gràcies a matrimonis, s'havien creat lligams familiars.

Tanmateix, el testimoni de dos documents de 1210 i 1211 deixa pensar que el seu nom originari fos Pere ${ }^{8}$, mentre la primera redacció de les Gesta Comitum ${ }^{9}$ li diu Petrus Iacobi. No vull creure que l'episodi narrat per Jaume de les espelmes sigui completament fals, però o no va esdevenir quan ell diu, o, si és així, el nom de Jaume el va decidir Maria i només ella, tal com apareix al seu testament ${ }^{10}$, i va ser el mateix rei Jaume que el va escollir com a únic, anys més tard. Perquè al 1211 es deia Pere, en línia amb la nominació tradicional aragonesa, i seguint els patrons d'elecció de noms del casal de Barcelona, al qual, al llarg dels dos últims segles el primogènit portava el nom del pare o, com a molt, el de l'avi. Mentre al 1214, any de la redacció de les notícies de les Gesta Comitum, encara, o ja, portava els dos noms. ¿Un altre cop és la mare qui canvia el nom? i ¿el fill accepta la voluntat materna ${ }^{11}$ ?

Després d'aquesta breu desviació, i per tornar al tema de la consciència dinàstica de Ramon Berenguer IV, diria que és possible trobar altres dades que confirmen, i reforcen, la meva hipòtesi inicial. És a dir que, en la consideració de Ramon Berenguer IV, el familiar títol comtal tenia preeminència respecte a les altres titolacions, reial inclosa. Al seu epitafi, el comte, fingidament, s'autodefineix, en un climax ascendent, com "Dux ego de matre, rex coniuge, marchio patre" ${ }^{12}$ : els seus tres títols són elencats en ordre del menys important, el de comte de Provença, a l'adquirit per matrimoni, la corona de l'Aragó, fins el més prestigiat de tots, el llegat familiar de comte de Barcelona, expressat amb la arcaica denominació de marchio. Això, al contrari de l'adveració testamental, o de l'epitafi que era contingut a la seva

${ }^{8} \mathrm{Vg}$. Joaquim Miret I SANS, Itinerario de Pedro I de Cataluña, II en Aragón, (2 ${ }^{a}$ part), «Boletín de la Real Academia de Buenas Letras de Barcelona», 4 (1907-08), pp. 15-36, 91-114, p. 17 (primera part, 3 (1905-06), pp. 79-88, 238-249, 265-284, 365-388, 435-450), i Ferran SoldeVILA, Jaume I. Pere el Gran, Barcelona, 1985 (1 ${ }^{\text {a }}$ ed. 1955), Biografies Catalanes 5, p. 1 i p. 69, n. 3.

${ }^{9}$ Gesta Comitum Barcinonesium, ed. L. BARRAU DiHIGO; J. MASSÓ TORRENTS, Barcelona , IEC, 1925, pp. 16, 18 i 19, en tinc en preparación una nova edició crítica.

${ }^{10}$ Alexandre TEULET; Joseph de LABORDE; Élie BERGER; H.-François DELABORDE, Layettes du Trésor des Chartes, 5 vols, Paris, 1863-1909, doc. 1044.

${ }^{11} \mathrm{Vg}$. SOLDEVILA, Jaume I, p. 2.

${ }^{12}$ Lluís Nicolau D'OlWer, L'Escola poètica de Ripoll en els segles X-XIII, «Anuari de l'Institut d'Estudis Catalans», 6 (1915-20), pp. 3-84, p. 36. 
tomba on el climax era descendent ${ }^{13}$, sense que canviii l'escala d'importància dels seus títols. També el poema Fulgent nova per orbem gaudia se li dirigeix: "Per te, comes Barchinonensium, | idem princeps Aragonensium, | dux Tortossae, rex Illerdensium" (vv. 12-14) ${ }^{14}$.

Ramon Berenguer IV sembla mostrar com una certa recança en deixar les tradicions familiars, posar-les en segon nivell, per abraçar completament la nova dignitat reial. Però, a començar pel seu fill Alfons, l'ordre serà sempre el contrari, per donar prelació a la titolació reial.

Tot i que, doncs, entre el Ramon Berenguer de la història i el de Desclot, les formes del sentiment semblen ésser força semblants, possiblement, no ho són per les mateixes raons. És ben probable, a més, que Desclot inventi la frase cèlebre suara citada després d'haver comprovat que Ramon Berenguer no va assumir la titolació regal. D'altra banda, no sé si en aquesta insistència sobre el llinatge del comte de Barcelona hi hem de veure també, en Desclot, un reflex de sentiments sortits a les Corts de Barcelona de 1283 a les quals Pere II "es veié obligat a ratificar l'oficialitat del títol de Comte de Barcelona" 15 davant l'ambigüitat del títol de príncep a vegades utilitzat pels comtes ${ }^{16}$ : "XXIX. Item volumus et concedimus quod deinceps tam in litteris quam cartis et sigillis nostris scribamus nos et successores nostri Comitem Barchinone" ${ }^{17}$.

13“"Raymundus Berengarii Comes Barchinonensis, Princeps et Rex Aragonensis, et Dux Provinciae" (P. FLóREZ, España Sagrada, 43, Madrid, 1819, p. 466) i com és també entrat als inèdits annals continguts al ms. Biblioteca Universitària de Barcelona 588, fol. $39 \mathrm{r}$ (Annals de Ripoll II) -d'aquests i de tots els altres annals citats es trobarà edició crítica al portal Historiografia a la Corona d'Aragó de la Biblioteca Virtual Joan Lluís Vives. Al poema Mentem meam ledit dolor, fins i tot és absent el títol reial: l'anònim poeta ripollès esmenta les conquestes de Siurana, Tortosa, Lleida i Fraga, a més de les efímeres de Lorca i Almeria, cita els honores de Barcelona, Țarragona, Arles i Tarascona, però mai nomena l'Aragó (NICOLAU, Escola poètica, pp. 36-38). És notable la coherència que trobem, amb l'èmfasi posada en les conquestes i en el patrimoni del llinatge, amb les idees expressades per Desclot al pròleg de la seva crònica que analitzo més avall.

${ }^{14}$ Salvador MARTíNEZ, Épica románica en Cataluña. Reliquias de una tradición latina, «Studia in honorem prof. M. De Riquer», IV, Barcelona, 1991, pp. 25-67, p. 46.

${ }^{15}$ ABADAL, Pere el Cerimoniós, p. 64.

${ }^{16}$ Seria exagerat definir aquests sentiments com de 'nacionals', tanmateix la Crònica de Desclot revela notables tensions entre Catalunya i Aragó que es podrien dir nacionals, si per nacionals entenem la consciència de pertànyer a sistemes político-econòmics diferents amb diverses tradicions històriques. És evident que tal sentit d'autonomia no s'expressava segons aquests conceptes moderns.

${ }^{17}$ Cortes de los antiguos reinos de Aragón y de Valencia y Principado de Cataluña, Cortes de Cataluña, I, Madrid, 1896, p. 149; vg. també SolDEVILA, Jaume I, p. 132. 
Tanmateix, la reiteració en rellevar el valor del llinatge comtal, tot i per diferents raons, al llarg de 150 anys, em sembla ésser prova suficient bé de la importància d'aquest sentiment, bé de les relacions i equilibris no gaire senzills entre les dues meitats 'històriques' que formaven la Corona d'Aragó: el 'regne' d'Aragó i el 'comtat' de Barcelona ${ }^{18}$.

\section{BERNAT DESCLOT I LA REIALESA}

Per tal de poder copsar millor bé les intencions de l'historiador, bé les arrels tradicionals sobre les quals treballa, i també la manera en què aquestes es creuen, és necessari analitzar des de més a prop el pròleg de la crònica de Desclot, que, pel que em sembla, no ha cridat l'atenció de cap estudiós i que, al contrari, ofereix nombrosos punts d'interès justament per plantejar l'evolució del sentiment dinàstic dels comtes de Barcelona, sobre quins valors es recolza, i segons quins argoments i formes acull l'heretat aragonesa i se'n diferencia ${ }^{19}$. Hem de tenir en compte que els pròlegs tenen tot sovint un especial significat ideològic i que les afirmacions en ells contingudes poden presentar un relleu ben especial, de manera que no debades és necessari analitzar-los en profunditat. S'ha d'afegir que les idees expressades per l'exordium poden ser tant historiogràfiques com polítiques.

Desclot comença la seva crònica escrivint:

Assí comensa lo libre qu·En Bernat Desclot dictà e escriví dels grans feyts e de les conquestes que feeren sobre saraÿns e sobre altres gens los nobles reys que hac en Aragó qui foren del alt linyatge del comte de Barcelona (Pròleg).

\footnotetext{
${ }^{18}$ A CingOLANI, Historiografia, propaganda, passim analitzo els sentiments 'antiaragonesos' que emergeixen a la crònica de Desclot, sobretot en relació a la guerra contra Felip III.

${ }^{19} \mathrm{He}$ pogut descobrir que de la crònica de Desclot ens ha arribat dues redaccions diferents. Una primera, redactada entre 1282 i 1285 , és transmesa només pel ms. Biblioteca de Catalunya 152. Mentre la que es llegeix normalment a les edicions impresses és una segona redacció, producte de la revisió de la seva primera feina, duta a terme entre els anys 1286 i 1288 . Les diferències entre les dues redaccions són, a vegades, notables i importants, i les estudio en detall a CingOLANI, Historiografia, propaganda. Al no haver-nos arribat cap pròleg de la primera redacció de la crònica no es pot saber què hi deia, així que ens hem de limitar a considerar què escriu a la segona redacció. Per enfocar unes diferències bàsiques entre models de passat, pel que fa a Catalunya i Aragó, vg. Thomas N. BISSON, Unheroed Pasts: History and Commemoration in South Frankland before the Albigensian Crusades, «Speculum», 65 (1990), pp. 281-308.
} 
Un element que s'ha de destacar, de l'encapçalament de l'obra, és el de les conquestes que, com a subjecte de la narració, és determinant de cara a l'estructuració i la perspectiva de tot el llibre, i va estrictament lligat a la decisió de voler parlar només dels reis -en aparent contradicció amb la importància donada a l'antiguitat del llinatge comtal. És a conseqüència d'aquesta elecció que Desclot no parla dels que foren només bé 'comtes' de Barcelona o bé 'reis' d'Aragó ${ }^{20}$. Desclot vol subratllar les grans ampliacions territorials de la corona que són exactament les conquestes de Mallorca, de València, de Múrcia i de Sicília, totes fetes pel casal de Barcelona quan ja eren reis d'Aragó, i no només comtes de Barcelona, puix les adquisicions de Ramon Berenguer IV són gairebé silenciades, tot i que és justament amb aquest comte, el Sarracenorum triumphator, que coincideixen en una mateixa figura la consciència del llinatge, l'adquisició de la corona reial i les primeres grans ampliacions territorials. M'explico amb més claredat i precisió.

Això que vol Desclot és posar la dinastia a l'alçada dels altres grans casals monàrquics europeus, $\mathrm{i}$ aquests són reials o imperials, no pas comtals. Però, i al mateix temps, també defensa i n'exalça l'antiguitat del llinatge, gairebé distingint dos aspectes, el de la sang, l'alt linyatge, i el dels èxits, les obres dels nobles reys, diferenciant, a propòsit del significat de la noblesa, entre nissaga i valor, de manera prou coherent a la que trobarem a les Gesta Comitum $^{21}$.

\footnotetext{
${ }^{20}$ Aquest plantejament de Desclot sembla haver tingut èxit sobretot a finals del segle XIV, i és recollit pel futur rei Martí I a una carta que envia al seu germà, Joan I, al 1392, vg. Miquel COLl I AlENTORN, Historiografia, Barcelona, 1991 (Obres I), pp. 310-312- i, en menor mesura, al seu parlament a les Corts de Perpinyà de 1406, Ricard ALBERT; Joan GASSIOT, Parlaments a les Corts Catalanes, Barcelona, ENC, 1928, pp. 58-72.

${ }^{21}$ Les citacions de les Gesta Comitum les faré de la següent manera: GCB I, correspon a la versió primitiva, composada en diferents etapes entre $1180 \mathrm{i}$ poc abans la mort de Jaume I; GCB II, a la llatina intermèdia només transmesa per la traducció al català de 1268-69; GCB III, correspon a la versió definitiva, redactada en dos o tres moments diferents entre $1280 \mathrm{ca}$. i 1300 ca.; GCB IV, a la redacció que COLL, Historiografia, p. 331, defineix com a redacció ampliada, de la qual edito uns capítols a Stefano Maria CINGOLANI, Historiografia catalana al temps de Pere II $i$ Alfons II (1276-1291). Edició $i$ estudi de textos inèdits: 3. Gesta Comitum Barchinonensium IV, «Llengua \& Literatura» 15 (2004), pp. 7-30, i que s'ha de datar al 1276-1282 ca. GCB IV, és transmesa de forma fragmentària per tres manuscrits, Biblioteca der Catalunya 152, Biblioteca de Catalunya 487 i Biblioteca Nacional de España 1814, i és difícil determinar-ne exactament l'extensió ja que als mss. a partir del relat del regnat de Pere I és en part, o completament, substituïda pel text de Desclot, el de la primera redacció a BC 152, i de la segona a BC 487 i BNE 1814. Aquesta redacció és de la més gran importància perquè és font directa de Desclot. La estudio més en detall, intentant definir-ne els límits i el significat a Stefano Maria CINGOLANI, Historiografia catalana al temps de Pere II i Alfons II (1276-1291). Edició i estudi de textos inèdits: 5. La Crònica de Sant Pere de les Puel-les $i$ les Gesta Comitum Barchinonensium IV, «Boletín de la Real Academia de Buenas Letras de Barcelona», 50 (2005-2006).De GCB II i de GCB IV, amb el nom de Libre dels reis, n'estic preparan l'edició crítica.
} 
Aquesta declarada voluntat d'exaltació dinàstica presenta també una vessant especificadament historiogràfica, ja que els fets i les conquestes permeten de sortir, de tots els punts de vista, de l'estricta dimensió local i familiar que -tot i uns matisos que veurem més endavant- presentava la redacció primitiva de les Gesta Comitum, obra que, d'alguna manera, Desclot dona com a coneguda ${ }^{22}$. Explicar la recentment aconseguida dimensió europea de la monarquia es podia fer, doncs, gràcies a la narració sobretot de les conquestes, que a les Gesta Comitum -primera i segona redacció- són narrades de manera força eixuta, i que al Libre dels fets tenen tota un'altra perspecti$\mathrm{va}^{23}$.

Tanmateix, Desclot treballa a partir de les mateixes Gesta Comitum, perquè, com ja trobem al pròleg de la versió intermèdia i al de la versió definitiva, aquestes diuen:

Aquest libre mostra veritat (...) dels fets recaptoses e grans e nobles qui són estats feyts per comtes e per reys en lur temps (GCB II, 119).

Iste liber ostendit ueritatem (...) Item ponuntur in eo facta et gesta nobilia quae fuerunt facta per reges Aragoniae suis temporibus et per nobiles comites Barchinonae (GCB III, 23).

L'exordi de Desclot pareix ésser una variació amplificada del de les Gesta Comitum, sobretot tal com el transmet la versió llatina, especificant que les gesta són conquestes, que és un dels aspectes que més l'interessa destacar en la seva imatge de la reialesa catalana, i variant el doble gesta nobilia / nobiles comites del text llatí en grans feyts i alt linyatge.

\footnotetext{
${ }^{22}$ Ja n'existien, quan escriu Desclot, també les dues versions en català, GCB II i GCB IV, així que també el seu potencial públic laic les podia conèixer. Potser no és pas per casualitat que almenys a tres manuscrits antics (BNE 647; BUB 759; BC 943) la Crònica de Desclot és precedida per la versió catalana de les Gesta Comitum, i n'hi han d'altres que són compilacions a les quals aquestes dues obres estan integrades l'una a l'altra, a més d'afegir materials que provenen de Muntaner i d'altres fonts, com ara les ja citades compilacions contingudes al ms. BC 152, vg. Jordi RUBIÓ I BALAGUER, Historia i historiografia, Barcelona 1987 (Obres VI), pp. 192255 i CINGOLANI, Historiografia catalana 3-i al BC 487, conegut com a Libre de les nobleses dels reys de Francesc, vg. Coll, Historiografia, pp. 314-346-, o al BNE 1814 que no és altra cosa que una versió al castellà d'un primer estadi de la compilació de Francesc.

${ }^{23}$ Evidentment és present, sense ser massa desenvolupat, el nucli lligat a Ramon Berenguer IV, amb l'expedició a Almeria i les conquestes de Tortosa, Lleida, Fraga i Siurana, és a dir el completament de la reconquesta de la Catalunya Nova, nucli present a tots els reculls d'annals catalans i que gairebé existeix com a grup de notícies aillat i compacte, com mostren els 'cronicons', millor annals, de San Cugat i de Skokloster (vg. Coll, Historiografia, pp. 65-92).
} 
Desclot, també, posa per raons de protocol cancelleresc i de prestigi, evidentment, en primer lloc el títol reial, però destaca, més enllà de les formules cerimonials, i d'acord amb les paraules de Ramon Berenguer IV que he citat més amunt, la força de l'antiguitat del llinatge. Aquesta l'hem d'entendre com a consciència genealògica de l'origen llunyà de la família, com a continuïtat de la transmissió del poder i de la noblesa -més enllà del senzill títol honorífic- al llarg de les generacions dintre d'una mateixa línia de descendència patrilineal, i com a vertadera consciència aristocràtica més que política. D'altra banda, em sembla possible veure un eco de les Gesta Comitum ja al títol mateix de l'obra de Desclot -que no és el modern i abreujat Crònica sinó Libre del rey En Pere de Aragó e dels seus anteçesors passats-, en voler-se centrada sobre el rei Pere i els seus predecessors, que són antecessors en tant que pertanyen al mateix llinatge, i no, senzillament, en quant reis d'Aragó. En efecte, el primer protagonista de la seva obra és el Bon Comte de Barcelona, ara Ramon Berenguer IV, considerat al moment de merèixer la corona reial gràcies al seu valor, les seves conquestes i, justament, l'antiguitat de la seva sang.

\section{CONCEPTES DE NOBLESA:}

NOBLESA PER LA SANG O PER LA VIRTUT

Per entendre el més exactament possible el significat i el valor d'aquesta titolació, en especial a Desclot, i sobretot, com hem vist, pel que fa a l'adjectiu nobilis, n'haurem d'estudiar la utilització en altres textos, tot i que a l'alçada de finals del segle XIII ja no tenia la mateixa densitat semàntica que als segles X-XII ${ }^{24}$. A falta d'estudis de conjunt sobre el tema per a la situació a Catalunya als segles XII-XIII, em limitaré a analitzar algunes dades que ofereixen les tres redaccions de les Gesta Comitum ${ }^{25}$. Evidentment seran dades que poden tenir la seva significació únicament a l'interior de la terminologia historiogràfica, potser menys precisa i conscient que la documental, així que

\footnotetext{
${ }^{24}$ Ens ha d'inspirar una certa cautela l'observació de Alessandro BARBERO, L'aristocrazia nella società francese del medioevo, Bologna, 1987, p. 21 a propòsit de nobilis: "il cui uso, come vedremo, è troppo legato a variabili anche soltanto stilistiche per poter essere considerato realmente determinante".

${ }^{25} \mathrm{Vg}$. en general BARBERO, L'aristocrazia, pp. 15-69 amb amplia bibliografia, i pel període precedent a Catalunya Pierre BonNASSIE, Cataluña mil años atrás (Siglos X-XI), Barcelona, 1988 . pp. 382-406. 
és un moment de reflexió que haurà de trobar confirmacions o matisacions en estudis més amplis i de conjunt.

El primer text per analitzar és la redacció primitiva de les Gesta Comitum. Tot i tenir en compte les seves diferents fases de composició, tanmateix serà útil i còmode confrontar aquestes dades amb les de la versió catalana, GCB II que, recordo, s'ha de datar a entre 1268 i 1269, per veure la correspondència de la terminologia en català. Pel que fa a la versió definitiva, les GCB III, considerades les profundes remanipulacions a les quals els autors van sotmetre el text primitiu, serà més adient un tractament a part.

El fundador de la dinastia, Guifré és definit a la redacció primitiva com a miles, que en català es tradueix sense dubtar per cavaller (GCB II, 119), i s'afegeix que era: "hic igitur miles, diuitiis, armis et consilio opinatissimus" (GCB I, 3). Em sembla que és el cas de notar com per el primer autor de GCB I la condició de miles situa a Guifré en les capes altes de la noblesa feudal, tot i així encara no lligada a cap honor hereditari, que justament obtindrà el seu fill. Més endavant, a GCB I 12 i 15, milites / militibus designa genèricament soldats a cavall, que GCB II altre cop tradueix per cavaller, i defineix les capacitats amb les armes de Pere I, elogiat per la seva militia (GCB I, 18).

És també interessant destacar el possible valor del terme a finals del segle XIII tal com el fa servir el revisor de les GCB III d'aquesta secció, que escriu cap al $1280 \mathrm{ca}$. Per una banda, ara sembla quedar com a definitivament assumida la identificació entre nobles i cavallers, tot i la major ambigüitat del terme a aquesta època, i una aparent gradació de nivells ${ }^{26}$, amb l'expressió collecta nobilium militum maxima multitudine (GCB III, 29 i per exemple 94 nobiles milites). Per l'altra, la condició de miles sembla conferida de forma necessària a l'avantpassat fundador d'un casal - que sigui mítica o no la seva existència $^{27}$-, com podem comprovar a la següent notícia, relativa a la fundació del regne d'Aragó: "Fuit itaque quidam miles nomine Raimirus, filius Sancii regis Nauarrorum" (GCB III, 42).

El primer redactor de les Gesta Comitum, el que escriu -entre 1180 i 1184- la secció que va des del començament de la crònica fins al regnat de

\footnotetext{
${ }^{26} \mathrm{Vg}$. BARBERO, L'aristocrazia, pp. 53-57.

${ }^{27} \mathrm{Vg}$. Georges DuBY, La société chevaleresque, Paris, 1988 ( $1^{\mathrm{a}}$ ed. 1979), pp. 179-180 i Éric BOURNAZEL, Mémoire et parenté (le problème de la continuité dans la noblesse de l'an Mil), Robert DELORT; Dominique IogNA-PRAT (eds.), La France de l'an Mil, Paris, 1990, pp. 114124. 
Ramon Berenguer IV, no fa mai servir el terme nobilis, ja que, en el cas de l'aristocràcia utilitza termes més clàssics com ara magnates, proceres o optimates (GCB I, 4). La primera vegada que al text de les GCB I apareix nobilis ho devem a la ploma del segon redactor, de primers del segle XIII, i és a propòsit d'Alfons I de Catalunya, tot just coincidint amb l'assumpció del títol reial pel casal dels comtes de Barcelona ${ }^{28}$ :

\section{Ipse uero Ildefonsus rex Aragonensi nobilissimus et armis strenuissimus et} acri ingenium fuit (GCB I, 13).

El tercer redactor de la versió primitiva parla de la uirtus nobilitatis (GCB I, 16) de Pere I, que tornarem a examinar més endavant, i el quart del cor nobile de Jaume I i de nobiles uiri (GCB I, 19), amb el primer i el segon cas que ja defineixen una qualitat ètica, mentre el tercer assenyala, genèricament, la noblesa ${ }^{29}$.

Més complexe i ambigu és el cas dels Usatges de Barcelona ${ }^{30}$. La terminologia és variada i no sembla correspondre's sempre amb precisió amb una categoria concreta en l'estratificat món que s'hi descriu. Hi apareixen magnates (us. 4.1 etc.) que, en principi, representen els grans barons del comtat, els milites et cavallarii (us. 5, 7 etc.) que són l'esglaó més baix de la part alta de la societat: són els cavallers, més en el sentit dels qui combaten a cavall que de petita noblesa, tot $\mathrm{i}$ que no és sempre fàcil decidir-se $\mathrm{i}$ diferenciar. A l'us. 12 apareixen els nobiles que són el conjunt de magnates seu milites (també a us. 24, 29, 46, 64, 97), aquells que serien els nobilium uirorum (us. 64) del consell.

La presència de fórmules com omnes homines, tam milites quam rustici (us. 50), o nobiles et ignobiles (us. 12, 61, 64, 91) deixa entendre amb

\footnotetext{
${ }^{28}$ Potser és una casualitat, potser no, però al Cronicon Dertusense II, a Jaime VILLANUEVA, Viage literario a las iglesias de España, 22 vols., Madrid, 1803-1852, V, pp. 236-240-, nobilis apareix referit només a Alfons i a la seva esposa, Sancha: "Era -MCCXXXIIIII, anno -MCXCVI. obiit Ildephonsus nobilis rex Aragonenensis" i "Era 'MCCXLVI', anno · MCCVIII- obiit domina Sancia regina nobilis Aragonensis".

${ }^{29}$ Ús aquest que és el més normal, per exemple als annals ja citats del ms. BUB 588, en la part que apareix el terme nobilis redactats al llarg del segle XIII: a fol. $41 \mathrm{r}$ és Jaume I que conquereix València "cum magno exercitu, archiepiscoporum, et episcoporum et multorum aliorum nobilium", a fol. $41 \mathrm{v}$ és Carles d'Anjou que "cum magna multitudine militum nobilium decollatur" Conradí; mentre trobarem nobilis en sentit ètic a la notícia de la mort de Pere II, "nobilis Petrus rex" el qual "prepotentem nobili potentia cordis fui[t]" i és recorden els "facta et nobilia gesta" (fol. 42 r) que estan escrits a les Gesta Comitum. 1991.

${ }^{30}$ Usatges de Barcelona. El Codi a mitjan segle XII, a cura de Joan BASTARDAS, Barcelona,
} 
prou claredat que la societat és dividida en dues parts. A una hi ha els rustici et pagenses, mercerii et negociatores (us. 64) els rustici (passim), o els burgensium (us. 56). Aquests serien els ignobiles en contrast amb l'altre sector, el dels nobiles, els maganats i els cavallers. Però les fronteres no semblen ser tan netes ni socialment marcades amb rigides fronteres. És a dir, que són nobiles els milites perquè van a cavall i exerceixen la guerra, respecte als que tenen feines pacífiques dels quals són diferenciats, puix es diu que omnis hominibus exceptis militibus, scilicet de burgensibus et de baiulis atque de rusticis etc. (us. 102).

Tot i així es parla de exorchie nobilium uidelicet et magnatum, tam militum quam burgensium (us. 69). És a dir que els burgesos, aparentment quan són molt rics, poden formar part de la capa alta de la societat. Així que es distingeix entre militum (...) ciuium et burgensium et nobilium baiulorum (...) rusticorum (us. 112) sense que sigui clar perquè els batlles poden també ser nobles, si són rics, com els burgesos, o perquè ja eren nobles abans d'exercir el càrrec. Si els nobiles formen la capa alta d'una societat tripartita dominada pel principe, no sempre és clar on posar la frontera, si respecte al poder econòmic o a les funcions. L'única raonable certesa és que el terme no és encara caracteritzat socialment de manera ineqüívoca en el sentit, modern, de la noblesa.

Per tornar a les Gesta Comitum, es pot veure com a la versió catalana el terme sembla ser més fluctuant i imprecís, i amb menys significat, tot i fer servir, per a la traducció, tot sovint termes més concrets i precisos respecte al genèric, o ambigu, nobilis. El primer cas, esmentat més amunt, d'utilització de nobilis, a les GCB I, el referit a Alfons I a GCB II hi és suprimit. El segon exemple és traduït per fets valerosos (GCB II, 139) -per confrontar amb el pròleg citat més amunt-, es manté el cor noble de Jaume I i es tradueix els nobiles uiri per molt rich hom (GCB II, 143). Finalment, es gira en noble senyor Ramon Berenguer comte de Barcelona (GCB II, 138) el Raimundi Berengarii bone memorie incliti Barchinonensis comitis (GCB I, 15).

Sintetitzant, i d'acord amb el que emergeix d'altres estudis, es pot destacar com, a partir del principi del segle XIII, nobilis assenyala amb claredat una condició de preeminència social, sobretot pel seu aspecte moral, 
més que per una condició de classe establerta, mentre amb anterioritat el terme no era gaire utilitzat, i mai pel primer redactor de les Gesta Comitum ${ }^{31}$.

A la redacció definitiva, com ja hem vist, trobem utilitzat miles com a les altres (GCB III, 23), mentre el terme que canvia i s'estén, en quant a significats i implicacions, assumint més decidit protagonisme, és el de nobilis. Al pròleg l'autor ja parla de Barchinonensium nobilium principum (GCB III, 22) i de nobiles comites Barchinonae (GCB III, 23) ${ }^{32}$. A continuació trobem que Ramon Berenguer I és nobilissimus comes (GCB III, 32), i Ramon Berenguer II és nobilissimum comitem (GCB III, 36), coincidint amb el moment mític definit amb la promulgació dels Usatges de Barcelona.

Però, a partir de Ramon Berenguer III, nobilis apareix de manera estable ja a les rúbriques dels capítols: GCB III, 37 ( i a 38), i per Ramon Berenguer IV (GCB III, 38 i 41). Aquest canvi en la denominació dels comtes coincideix amb l'ambigua figura del Bon Comte de Barcelona que apareix a Desclot, assenyalant, possiblement, la posició predominant que ja havien assolit pare i fill, almenys a la memòria històrica del Principat, sinó també a la col·lectiva. S'ha de notar, i no serà pas per casualitat, que els reis d'Aragó ante unionem, del quals fa una breu història a continuació, no són mai denominats com a nobiles, coincidint així, d'alguna manera, amb la diferència en el tractament que li havia reservat Desclot.

Tornem a trobar el títol a les rúbriques d'Alfons I (GCB III, 45), de Pere I (GCB III, 50) i de Jaume I (GCB III, 56), quan Pere II, heroi central també de les GCB III, és nobili ac strenuissimo (GCB III, 61). De manera tal

${ }^{31}$ Per analitzar la presència de nobilis en textos literaris anteriors, podem notar com a l'acta de dedicació de Ripoll del 977 Guifré I és definit com "carus patricius, vir nobilitatis titulo pollens", Josep Maria SALRACH, El comte-bisbe Miró Bonfill i l'acta de consagració de Ripoll de l'any 977, «Estudis Universitaris Catalans», 26 (1984), pp. 303-318 («Miscel-lània R. Aramon i Serra», IV), p. 307; cap al 1018, l'abat Oliba al seu poema fúnebre per Ramon Borrell, $A d$ carmen populi flebile cuncti, no fa mai servir nobilis, mentre assenyala el comte com a procer (Eduard JUNYENT I SUBIRÀ, Diplomatari i escrits literaris de l'abat i bisbe Oliba, Barcelona, IEC, 1992, pp. 301-304). Als contemporanis Disticha epitaphia comitum Rivipullo quescentium, apareix nobile pignus (v. 17) referit a a Ermengol fill del comte Sunyer de Barcelona, nobilis atque comes referit a Guifré II de Besalú (v. 22) i nobile corpus a Seniofred de Cerdanya-Besalú germà de l'anterior, en el tres casos amb un prou clar significat moral (JUNYENT, Diplomatari, pp. 304-307). A una carta del 22.9.1040 Oliba es dirigeix a Arnau Mir de Tost com a viro nobili et sapienti (JUNYENT, Diplomatari, pp. 338), però mai empra nobilis parlant de Bernat Tallafer comte de Besalú i cosí seu, terme que tampoc apareix als poemes dedicats a Ramon Berenguer IV.

${ }^{32}$ Més endavant trobem que Oliba Cabreta tenuit comitatum nobiliter (GCB III, 28), traduït a les GCB II, 123 amb el normal poderosament, amb una significació, doncs, especial, ailllada potser limitada a aquesta cas, ja que és l'únic comte no de Barcelona al qual se li atribueix la títolació de noble, tot i que com a adjectiu. 
que, pel que sembla, el títol de nobilis assumeix de forma estable un valor honorífic distintiu del llinatge dominant del casal de Barcelona, i li reconeix un estatut de superioritat també respecte als reis d'Aragó abans de la unió.

En canvi, nobilis no apareix a les rúbriques d'Alfons II (GCB III, 94) i de Jaume II (GCB III, 102). Alfons II, tanmateix, com els primers dos Ramon Berenguer, al text és caracteritzat com a rex iuuenis et nobilis (GCB III, 95), i nobilis regis nostri (GCB III, 97 i 102), mentre Jaume II és nobilis a GCB III, 102, que correspon a l'últim capítol de la vida d'Alfons II, però mai a la seva secció, on, al contrari, són nobles el seu fill Pere nobilis infans Petrus (GCB III, 110) i el germà Frederic (GCB III, 113), quan Jaume és sempre només dominus rex noster. Aquestes diferències són degudes, sense que de moment sigui possible precisar, tant a una aparent insatisfacció amb el regnat d'aquests dos monarques, que possiblement portà a una brusca interrupció de la crònica, com a un canvi d'autoria ${ }^{33}$.

Per tornar a Desclot podem comprovar que les dades extretes de les Gesta Comitum coincideixen parcialment amb l'ús que en fa el cronista en vulgar, ja que aquest manté nobilis com a títol honorífic, que, es diria, ve de, i pertany a, la monarquia, però ressalta, en una perspectiva encara més marcadament feudal, l'importància determinant de l'alt linyatge.

No sé si ens trobem davant d'una resposta al debat que hi havia respecte a l'origen i la justificació de la noblesa, si per la superioritat de les seves virtuts morals o per l'antiguitat de la seva sang ${ }^{34}$. Els dos conceptes són, al cap i a la fi, d'origen clerical, tanmateix el primer, el del privilegi de la noblesa a causa de les seves virtuts morals, és el que més arrelarà en ambients no nobiliaris, i és el concepte amb el qual Desclot considera la monarquia per tenir unes tradicions, ja a l'Aragó i després al casal de Barcelona, més recents i que s'han de justificar per les virtuts ètiques.

Mentre el segon concepte, el de l'antiguitat de la sang demostrable gràcies a una genealogia, que és aquell que més èxit trobarà a l'interior de la mateixa noblesa, és per Desclot utilitzat per caracteritzar el casal de

\footnotetext{
${ }^{53}$ Per les GCB III es poden individuar almenys tres autors: un primer que revisa la part fins a Jaume I i la completa, poc després de 1276; un segon que compon la secció sobre Pere II, cap a 1286, i un tercer que segurament escriu la secció que es refereix a Jaume II, acabada després del 1299 , però no estic segur de qui és el responsable de la secció dedicada a Alfons II, si el segon o el tercer autor, vg. CINGOLANI, Historiografia, propaganda, pássim. Stefano Maria CINGOLANI, La memòria dels reis. Les quatre grans cròniques i la historiografía catalana des del segle X al XIV, Barcelona, 2006. .

${ }^{34} \mathrm{Vg}$. Alexander Murray, Ragione e società nel Medioevo, Roma, 1986 (ed. or. anglès 1978), pp. 281-290 i 331-342, i BARBERO, L'aristocrazia, pp. 283-311.
} 
Barcelona, que pot demostrar, gràcies a les Gesta Comitum, una continuïtat al poder que remunta als temps fundadors i mítics de Carlemany -tot i que aquest element no és mai utilitzat explícitament- o, més generalment $\mathrm{i}$ confusa, dels reis carolingis ${ }^{35}$. D'aquesta forma els comtes-reis compleixen amb tots els requisits, virtut i antiguitat, tot i que són diferenciats els dos aspectes que legitimen el domini de la nissaga, com a reis i com a comtes.

\section{IMITACIÓ DELS AVANTPASSATS COM A IDEOLOGIA REIAL}

El concepte de nobilitas, que hem pogut definir com a bàsicament de caràcter ètic, tot i ser lligat a les virtuts cavalleresques, assoleix, però, a les Gesta Comitum una dimensió més complexa que a Desclot, i més ideològicament marcada en sentit culturalment clerical, ja que va acompanyat a la dimensió dels antecessores com a objecte d'imitació, concepte clau a totes les redaccions de les Gesta Comitum. Potser no és pas una casualitat que la idea comenci a ser expressada tot just amb Pere I, considerada la seva cavallerositat, deixant de banda el primer rei, Alfons $\mathrm{I}^{36}$.

Tot i així, és molt possiblement a l'època del mateix Alfons I que es va elaborar el concepte per part dels clergues que per ell treballaven, juntament, com hem vist i veurem, amb altres característiques i valors de la reialesa lligats al comportament i no a la sang. Aquesta hipòtesis és estimulada per la presència d'una formula que apareix, justament a partir del regnat d'Alfons I, pràcticament a totes les constitucions de Pau i Treva, i a altres constitucions i confirmacions de privilegis:

per part d'Alfons I a les constitucions de Pau i Treva de Fondarella de 1173, i repetit a les de Girona de 1188: "In primis igitur, parentum meorum sequens exempla" 37 ; Pere I, Corts de Barcelona de 1200: "In primis igitur parentum meorum sequens exempla" ${ }^{38}$; Jaume I, Corts de

\footnotetext{
${ }^{35}$ Sobre el fet de la directa ascendència carolíngia o senzillament de remuntar a temps carolingis, vg. BOURNAZEL, Mémoire et parenté, i més endavant.

${ }^{36}$ En això es pot veure una certa coherència amb el que farà el mateix Desclot, que en parla només com a pur tràmit biològic entre dos personatges importants: el seu pare, Ramon Berenguer IV, i el seu fill, Pere I.

${ }^{37}$ Les Constitucions de Pau i Treva de Catalunya (segles XI-XIII), ed. Gener GonZALVo I Bou, Barcelona, 1994 (TJC, Lleis i costums, II/3), p. 77.

${ }^{38}$ Constitucions, p. 117. 


\begin{abstract}
Vilafranca de 1218: "predecessorum nostrorum sequentes vestigia"39; Jaume I, confirmació privilegis de Poblet, 1.9.1222: "sequens vestigia parentum nostrorum" 40 ; Jaume I, Corts de Tortosa de 1225: "In primis, parentum nostrorum sequentes vestigia" ${ }^{41}$; Jaume I, confirmació dels privilegis del monestir de Junquera i Rueda, 14.10.1225: "antecesorum nostrorum sequi vestigia cupientes" ${ }^{42}$; Jaume I, escull el monestir de Sixena per ser-hi enterrat, 3.4.1226: "antecesorum nostrorum sequi vestigia cupientes" ${ }^{43}$; Jaume I, Corts de Barcelona de 1228: "Volentes antecessorum nostrorum sequi vestigia et exempla" ${ }^{44}$; Jaume I, confirmació dels furs i dels privilegis de Saragossa, 14.3.1233: "antecessorum nostrorum sequentes vestigia" ${ }^{45}$; Jaume I, Corts de Tarragona de 1235: "Predecessorum nostrorum sequentes vestigia" 46 etc.; i, finalment, per Pere II a les Corts de Barcelona de 1283: "predecessorum nostrorum sequentes vestigia" ${ }^{47}$.
\end{abstract}

Això que s'hauria d'estudiar més en detall és l'evolució del concepte d'imitació dels antecessors i el seu passatge de senzilla formula legal, a la qual això que s'expressa és la imitació i la continuïtat d'una tasca legislativa, al concepte de imitatio morum, doncs més aviat ètic, amb la possibilitat àdhuc de la superació dels antecessors, i de quines connexions hi ha entre els dos aspectes. Perquè, en el cas de les constitucions de Pau i Treva, és veritat que, ja amb anterioritat, els comtes hi havien participat, però ho és també que les de 1173 foren les primeres en què es tracta de la 'Pau del rei' i ja no de la 'Pau de Déu', de forma tal que s'hauria d'apreciar més l'aspecte innovador que no el continuïsta ${ }^{48}$.

${ }^{39}$ Constitucions, p. 144.

${ }^{40} \uparrow$ Ambrosio Huici Miranda; María Desamparados Cabanes PeCourt, Documentos de Jaime I de Aragón, 5 vols., Textos medievales, València-Zaragoza 1976-1988, doc. 37.

${ }^{41}$ Constitucions, p. 153.

${ }^{42}$ HuicI, Documentos, doc. 74.

${ }^{43}$ HuICI, Documentos, doc. 78.

${ }^{44}$ Constitucions, p. 165 , i en català: "volents seguir las vestigias e'ls exemplis dels antecessors nostres", HUICI, Documentos, doc. 114.

${ }^{45} \mathrm{HuICI}$, Documentos, doc. 177.

${ }^{46} \mathrm{HuICI}$, Documentos, doc. 183.

${ }^{47}$ Cortes, p. 140.

${ }^{48}$ Es podria pensar que qui escriu el document fa referència no tant a la pràctica, més aviat episcopal, com a la teoria, aquesta sí comtal i 'principesca', expressada als Usatges, us. 64 Quonim per iniquum, us. 91 Auctoritate et rogatu i us. 133 Denique, amb una retòrica i una 
Malgrat això, aquesta confluència de conceptes, entre el burocràtic i l'ètic, ha de ser ben primerenca $i$ ha d'operar durant el regnat del primer comte-rei, perquè Alfons I és justament el rei que, culminant l'obra de la cancelleria de Ramon Berenguer IV, mana fixar les bases de la legitimitat dinàstica. És ell que ordena de posar sobre pergamí els actes dels predecessors que fonamenten aquesta legitimitat i, per això mateix, s'han d'imitar. En efecte, és durant el seu regnat que es comença a redactar el monument historiogràfic de la dinastia, les Gesta Comitum Barcinonensium, i que és compilat el Liber Feudorum maior, el monument burocràtic de la legitimitat dinàstica a titular-se amb els seus honores.

Però, com ja he dit, ni el primer autor de les GCB I, aquell que escriu fins el regnat de Ramon Berenguer IV, ni el segon, el que s'encarrega d'historiar el regnat d'Alfons I, no recullen encara la idea d'una imitació / confrontació amb els avantpassats, idea que a la historiografia comencem a trobar plenament desenvolupada a partir del tercer autor, que escriu cap a 1214, el qual escriu del rei Pere I:

uirtus nobilitatis ipsius nunquam esset contenta, antecessores suos largitate, fama, dignitate cupiens superare (GCB I, 16).

Afirmació represa amb variacions per les altres tres redaccions (GCB II, 139; III, 51 i IV, cap. x). Aquesta de la imitació / superació l'hem de veure com una idea clau de la ideologia reial, juntament amb el caràcter de conqueridor del rei. De fet, en el cas del rei Jaume I, és novament expressada la mateixa voluntat d'imitació i ara també de superació, perquè el rei vol eixamplar els seus dominis:

Dominus itaque Iacobus rex predictus, habens cor nobile et uoluntate imitandi suos predecessores et non minuendi regna sua, sed potius totis uiribus ampliandi (GCB I, 19).

Lo senyor en Jacme, rey davant dit, avén cor noble de ressemblar son linyatge e no en re minvar sos regnes, mas a tot son poder crexer (GCB II, 143).

Notem la traducció de predecessores amb son linyatge, en una perspectiva feudal i familiar semblant a la de Desclot. L'idea és mantinguda

ideologia que analitzaré més endavant, juntament amb altres documents, vg. Gener GoNZALVO I Bou, La Pau i Treva a Catalunya. Orígen de les Corts Catalanes, Barcelona, 1986, pp. 50-62. 
també pel revisor de la redacció definitiva, tot i que amb variacions retòriques i insistint, ell també, sobre el concepte de llinatge, ja que substitueix predecessores, que pot expressar continuïtat en una funció, amb generis, que assenyala, al contrari, amb un matis clàssic la mateixa continuïtat però a l'interior d'una família:

Dominus Iacobus rex predictus, cor gerens nobile, uestigia generis sui in bonis actibus sequi uolens, et in aliquo non minuere regnum suum, sed crescere toto posse (GCB III, 57).

Els autors de la versió definitiva apliquen aquest lloc comú també a Pere II -notem, tanmateix, que, un cop establerta la continuïtat en el càrrec reial de membres de la mateixa nissaga, torna a la terminologia de la primera redacció:

inclitus Petrus rex Aragonum, antecessores suos animositate nobili cupiens anteire, disposuit barbaras subire nationes extra limites regni sui (GCB III, 68).
A Alfons II:
Cupiens uero dominus rex Ildefonsus praedecessorum suorum facta nobilia imitari et sequi uestigia nobilis sui patris, ordinauit magnum nauigium (GCB III, 95).

\section{I, finalment, a Jaume II:}
Verum dominus rex noster, nobilis patris suis et aliorum praedecessorum suorum cupiens sequi uestigia, qui armorum strenuitate semper augmen- tauerunt iura et dominia regni sui (GCB III, 110).

No em sembla que el concepte de la imitació de les virtuts familiars per part dels nous reis hagi estat estudiat en la seva evolució i difusió. Així que em limitaré a apuntar algunes dades al meu abast, almenys per plantejar el problema i intentar emmarcar-lo en unes coordenades històriques i culturals.

El concepte de la imitatio moris maiorum, clau de la ideologia civil romana, pel que fa a la seva propagació a l'edat mitjana és sense dubte d'origen clerical, sigui pel mateix plantejament, l'adequació d'una successió patrilinear en el marc d'una dignitat moral, sigui per les seves fonts directes 
o remotes, que en aquesta època són més lectura de clergues que de laics, com per exemple Sal-lusti, entre les obres de més àmplia difusió:

saepe ego audivi Q. Maxumum, P. Scipione, praeterea civitatis nostrae praeclaros viros solitos ita dicere, cum maiorum imagines intuerentur, vehementissime sibi animum ad virtutem accendi. Scilicet non ceram illam neque figuram tantam vim in sese habere, sed memoria rerum gestarum eam flammam egregiis viris in pectore crescere neque prius sedari, quam virtus eorum famam atque gloriam adaequaverit (Bel Iug IV 5-6).

La possibilitat de la imitació va, doncs, estrictament lligada a la memòria de les gestes passades, justificant i motivant la necessitat del seu record. El passatge, des de la idea d'una senzilla memòria de les empreses dels antecessors, també en textos en vulgar ${ }^{49}$, a la necessària imitació de les mateixes gestes per part de la reialesa és breu. I és el necessari complement de la justificació sobre basis ètiques de la continuïtat del privilegi del poder.

Em sembla digne de nota el fet que aquest concepte apareix també lligat a la monarquia francesa, i sempre procedint d'ambients clericals, aproximadament a la mateixa època en què el trobem utilitzat per a la monarquia catalana en la figura de Pere $\mathrm{I}^{50}$. No crec que hi haguessin contactes entre la cancelleria capeta, al nord de França, i la dels comtes de Barcelona, a l'extrem sud d'aquell que havia estat el regnum Francorum. Em sembla més probable veure-hi, en aquest paral-lelisme, el fet que la ideologia monàrquica és influïda per uns mateixos models i segueix uns mateixos patrons, almenys pel que fa a la seva elaboració a l'interior d'ambients cancellerescos i clericals.

En àmbit català la idea, pel que sembla, es va estenent i estabilitzant com a valor característic de la monarquia, també recuperant el valor genèric de la memòria. Un fet, aquest, de consciència historiogràfica acompanyada a la imatge del poder, que conduí a inserir un pròleg a la redacció definitiva de les Gesta Comitum manllevat directament, només amb petites variacions, del Pròleg de la Historia Gothica de Rodrigo Jiménez de Rada:

${ }^{49} \mathrm{Vg}$. Stefano Maria CINGOLANI, "Pour remenbrer des ancessurs", ovvero: Goffredo di Monmouth e Wace fra historiae e aventures, Storiografia e poesia nella cultura medievale, Roma, 1999, pp. 81-95.

${ }^{50} \mathrm{Vg}$. Andrew W. LEWIS, Le sang royal. La famille capétienne et l'État, France, Xe-XIVe siècle, Paris, 1986 (ed. or. anglès 1981), pp. 165-177. 
gesta etiam principum, quorum aliquos ignauia fecit uiles, alios sapientia, strenuitas, largitas et iustitia futuris seculis commendauit, ut quanta sit differentia utrorumque exitu comprobetur, et discant posteri bonorum exemplis inniti et a malorum semitis declinare; (...) Gloriosa etiam gesta et proelia aliorum mundi principium et gentilium, quae in mundo uarietate mirabili claruerunt, sine scriptura a memoria excidissent; igitur ne origo Barchinonensium nobilium principum praesentibus ualeat obliuisci et posteris ignorari, scriptura uolumus declarare (GCB III, 22).

Considerada la regularitat amb la qual és expressat el concepte de la imitació de les gestes dels avantpassats, també amb l'aspecte de l'ampliació dels dominis, em sembla extremadament interessant el fet que trobem aquesta mateixa idea aplicada als monarques catalans en altres cròniques que no provenen de Catalunya. En primer lloc, la retrobem expressada justament a Rodrigo Jiménez, on és atribuïda a Jaume I:

Rex vero Iacobus emulatione magna contendens parentum magnolia superare (HrH VI, 5).

No em sembla inútil destacar que les fonts d'aquests capítols han de ser de provinença catalana i, doncs, reial $^{51}$.

A la Chronica de Saba Malaspina, que escriu a mitjan 1285, aquest mateix argument el trobem utilitzat per part dels ambaixadors catalans, que des de Alcoll van a la cort del Papa, al juliol/agost de 1282, amb l'objectiu de demanar un últim cop suport per a la pretesa croada, abans d'iniciar l'expedició siciliana:

Ecce, pater sanctissime, dompnus Petrus rex noster merita cupiens adequare parentum et eorum per omnia vestigia laudabilia prosequi ${ }^{52}$.

Val la pena de notar com a Desclot, al text de la mateixa missatgeria, reportada al capítol 85, aquest concepte és absent. Saba Malaspina treballava a la Cúria i és possible que relati, si fa no fa, el text autèntic del missatge. També retrobem la idea a la Historia Sicula de Nicola Speciale, de mitjan segle XIV. L'historiador narra com, un cop esclatada la revolta de les Vespres

\footnotetext{
${ }^{51}$ Rodrigo JimÉNEZ DE RADA, Historia de rebus Hispanie sive Historia Gothica, ed. Juan FERNÁNDEZ VALVERDE, Tournhout, 1987 (CCCM, 72).

${ }^{52}$ Saba Malaspina, Die Chronik, ed. Walter KolLER; August NITSCHKE, MGH SS XXXV, Hannover, 1999, IX, 10. 
Sicilianes a Palerm, davant dels dubtes respecte a què fer, apareix un vell desconegut que aconsella els sicilians de demanar ajuda al rei Pere:

Nam illustris Petrus Rex Aragonum, vir utique magnanimus \& bellis assuetus, gloriosi genitoris sui regis Jacobi sequens vestigia, contra infideles Christi cum magna classe profectus apud Ancollem, ut fama refert, prospera bella gerit ${ }^{53}$.

També es pot relacionar, d'alguna manera, aquesta idea amb el que escriu el Papa Urbà IV a Jaume I a l'hora del plantejat, i després realitzat, casament de l'infant Pere amb Constança de Sicília, en una carta del 26 abril de 1262:

Sane, fili charissime, tuam tuorumque progenitorum devotionem ad memoratam ecclesiam frequenter operis exhibitione probatam, fratrum nostrorum et communi testimonio novimus, ipsamque ac tuam, et eorumdem progenitorum facta magnifica, quae ad exaltationem sui nominis, et Christiani cultus ampliationem dignata est dextera Domini, tuo et ipsorum ministerio, misericorditer operari, habentes in apostolicae mentis conscripta sacrario; (...). Considera, igitur, fili, considera tui generis claritatem, quantaque diebus antiquis, quorum memoriam non existit, generositate illustris claruit domus tua: quanta tibi dederit Dominus potentia, et persone strenuitate vigere: quot et quanti regiae dignitatis participes, tibi proxima consanguinitatis et affinitatis linea conjunguntur ${ }^{54}$.

A propòsit del que escriu el Papa, em semblen dignes de ser remarcats dos fets que, més enllà de la retòrica de la cancelleria papal, diria que tenen un significat precís. En primer lloc, que les fonts sobre la història de la família han de ser orals, communi testimonio novimus, i han de formar part de la presentació que els mateixos ambaixadors van fer al Papa, a part d'altres testimonis del seu entorn, fratrum nostrorum, així que les idees de la presentació han de procedir de la mateixa casa reial. En segon lloc, que el

\footnotetext{
${ }^{53}$ Nicola SpeCIALE, Historia Sicula, a Rosario GREgorio, Bibliotheca Scriptorum qui Res in Sicilia Gestas sub Aragonum Imperio retulere, I, Palermo, 1791-1792, p. 929E.

${ }^{54}$ Daniel GIRONA, Mullerament del Infant En Pere de Cathalunya ab Madona Constança de Sicilia, «Primer Congrés d'Historia de la Corona d'Aragó», I, Barcelona, 1909, pp. 232-299, pp. 269-271.
} 
papa afirma que memoriam non existit, i amb memòria es refereix sense dubte a la memòria escrita, no a la oral que alimenta tradicions ${ }^{55}$.

Em sembla, doncs, que es pot afirmar que l'idea de la imitació dels avantpassats, més enllà d'un lloc comú històric d'origen clerical, tantes vegades expressat a les Gesta Comitum, tampoc és senzillament una idea historiogràfica de l'anònim cronista del temps del rei Pere I, mantinguda pels seus continuadors i revisors. Al contrari, hem de pensar que possiblement ja a començar del regnat de Alfons I, i encara a les darreries del segle XIII formava part de la ideologia reial i que en alguns casos va ser utilitzat com a element de propaganda ${ }^{56}$.

Per concloure, doncs, podem notar com Desclot, tot i ser coherent amb la visió tradicional dels antecessors en la formulació del títol de la seva obra, es diferencia en part de la ideologia oficial en veure la continuïtat dels fets heroics des d'un altre punt de vista, utilitzant un concepte més laic i

${ }^{55}$ Que fora de la Península es tinguessin poques i confuses notícies, no basades en cap text escrit, sobre la història catalana és un fet indubtable. Només posaré tres exemples: a la vida d'Alfons I (XCII 1) es diu que Ramon Berenguer "conques lo regisme d'Arragon e•l tolc a Sarrazins", mentre una razo (XI L, 24-28) és encara més fantasiosa puix escriu que els comtes de Barcelona descendrien dels vescomtes de Carlat, vg. les edicions a Biographies des Troubadours, ed. J. BouTIÈRE; A.H. SCHUTZ, 2 a ed., Paris 1973 ( $1^{\text {a }}$ ed. 1964). Giovanni Villani, per la seva banda, resumeix així la historia de la corona d'Aragó -i, per la grafia dels noms, es pot deduir que havia de tenir fonts provençals o franceses-: "Quelli della casa d'Araona non furono anticamente di legnaggio reale, ma grandi conti furono, cioè conte di Barzellona e di Valenza; e come dicemmo addietro, l'antico loro, ciò fu il conte Anfuso, fu sconfitto e morto da' Franceschi a l'oste a Carcasciona al tempo del re Filippo il Bornio re di Francia. E dicesi ch'anticamente quelli d'Araona furono d'uno legnaggio col conte di Tolosa e del buono conte Ramondo di Proenza, ma poi il buono conte Giammo figliolo del detto Anfus e padre che fu del re Pietro che prese Cicilia, onde tanto avemo parlato, per sua prodezza e valore prese sopra Saracini di Spagna il reame d'Araona e uccise il loro re, e del loro reame si coronò, e popolò de' suoi Catalani, e fecelo uno colla Catalogna, e fu egli e sue rede confermato re d'Araona per la Chiesa di Roma" (Giovanni VILLANI, Nuova Cronica, ed. G. PORTA, 3 vols., Parma, 1990-1991, VIII LXXVI)

${ }^{56}$ I, com a tal, sembla tenir continuïtat dintre de la ideologia reial. Pere III, juntament amb la citació de Sal-lusti, el fa servir al document de donació dels seus llibres al monestir de Poblet (RUBIÓ, Historiografia, p. 447) o, per exemple, al parlament de les Corts de Montsó al 1363: "E jassia Déus no ens haja fets gran de persona, emperò la volentat e lo cor havem aitant gran e aitant bastant com negun cavaller qui sia e'l món, de morir o viure per defendre nostra corona e lo nostre regisme, lo qual, los nostres predecessors ab ajuda dels vostres e nós seguints les llurs petjades ab ajuda vostra, hi havem treballat en conquerir e guanyar" (ALBERT; GASSIOT, Parlaments, pp. 24-25) o encara a les de Montsó de 1383: "Que sien estats a llurs enemics, en defensió de llurs sotsmeses, ardits cavallers e triumfals, guardats les cròniques (...) e trobarets que (...) tot ho han conquest e guanyat d'infeels. Per què nós, volent seguir llurs petjades, havem volgut semblar en cascuna de les dites coses, nostres predecessors" (ALBERT; GASSIOT, Parlaments, p. 55). És un concepte que regeix també el llarg parlament de Martí I a les Corts de Perpinyà de 1406 (ALBERT; GASSIOT, Parlaments, pp. 58-72) o el de Pere Ferrer a les Corts de Tortosa de 1411 (ALBERT; GASSIOT, Parlaments, pp. 101-107) on es defensa la legítima successió de Jaume d'Urgell, fonamentant-se exactament en el principi de continuïtat amb, i imitació de, els avantpassats. 
feudal, com el del llinatge, i no tant curial com el de la imitatio, que descansa més en el concepte ètic de la noblesa que en el de la sang. L'única aparent excepció, dins la crònica de Desclot, la retrobem al discurs en què l'arquebisbe de Tarragona es dirigeix al rei Jaume, a les Corts preparatòries a l'expedició a Mallorca, quan el prelat diu:

e par bé del linyatge hon vós movets del prous chomte de Barcelona e de sos hereus, qui són estats de gran cor e de grans feyts e de nobleses, e vós, sènyer, volets éls ressemblar (cap. 15).

El concepte d'imitació prové, és clar, de les Gesta, una de les fonts de Desclot, i potser no és pas per casualitat que està posat a la boca d'un eclesiàstic. Tanmateix, Desclot posa èmfasi sobre la continuïtat del llinatge entre el Bon Comte, l'antecessor gairebé mític, i Jaume I. És la sang que mou a la imitació, i és la força del llinatge que es fa palesa en tots els seus membres. I Jaume I fa clara mostra de descendir del Bon Comte, del qual és relatada la efímera conquesta de Mallorca, exactament perquè en seguirà les petjades i l'exemple, amb un acte de conquesta. Així que, la voluntat de ressemblar-hi, esdevé un acte intrínsec a les qualitats del llinatge al qual el rei vol mostrar de pertànyer, com li diu el comte d'Empúries: "fèts atreyt al bon linyatge d'on vós sóts exit" (cap. 24).

\section{LLINATGE, PODER, HISTORIOGRAFÍA I MITES DELS ORÍGENS}

El testimoni de Desclot s'ha d'analitzar com a moment, i ben significatiu, de l'evolució de la consciència del llinatge del casal de Barcelona, i del lloc que prengué en aquesta consciència -i com en part la transformà- el fet de haver esdevingut reis. Investigació aquesta que, també, és encara tota per fer, i per la qual ara assenyalaré uns elements i unes etapes que em semblen significatives ${ }^{57}$. És aquesta una qüestió extremadament complexa,

\footnotetext{
${ }^{57}$ Escrivia Bisson que "dans le cas de la Catalogne, les fondements institutionnels qui se situent entre les conquêtes de Raimond Béranger IV et Jaume Ier restent a peu près inconnus" (Thomas N. BISSON, L'essor de Catalogne: identité, pouvoir et idéologie dans une societé du XIIe siècle, «Annales ESC» 39, 1984, 454-479, p. 454) i, malgrat tot, encara segueixen poc coneguts. El mateix Bisson al seu discurs pel conferiment del 'Doctor honoris causa' a la Universitat Autònoma de Barcelona, el 9 de maig de 1991, deĩa que, pel que fa a "la història del poder", a Catalunya "gairebé tot queda per fer", i afegeix que això no s'ha pogut fer: "per manca de registres i d'edicions crítiques com les que han permès als historiadors anglesos o francesos 
perquè, per a poder analitzar les representacions de la concepció del poder, s'hauria de poder comptar sobre un estudi de qual era, a la teoria i a la pràctica política del temps, aquesta mateixa concepció. Però, a part unes poques, lucidíssimes, denses i estimulants pàgines de Ramon d'Abadal ${ }^{58}$, no hi ha res d'exhaustiu ni de sistemàtic.

En efecte, l'adquisició de la corona aragonesa impulsa la reflexió respecte a les arrels i a la constitució del poder del llinatge, podriem dir que estimula un acte d'autoconsciència del casal. I hem vist que s'ha de veure aquest moment d'autoconsciència com a un moment de reflexió successiu i consegüent al conseguiment del títol reial, i que s'ha de fixar entre el segon i el tercer quart del segle XII, època a la qual remunten la redacció definitiva dels Usatges de Barcelona, la primera de les Gesta Comitum Barchinonensium i el Liber Feudorum maior.

Pel que fa a l'època anterior, el terreny és en bona mesura tot per investigar, i sobretot els diplomes podrien representar un ric camp d'investigació. Pel que fa a la producció literària, l'únic text precedent als esmentats que es podria comparar és un poema de l'abat Oliba, de ante 1018, els ja recordats Disticha epitaphia comitum Rivipullo quiescentium ${ }^{59}$. Tanmateix, el poema no mostra cap concepció del llinatge com a línia de descendència vertical, sinó que expressa el sentiment horitzontal de la família i del grup -de la família de l'abat-bisbe en concret-, concepció que, hem vist, és encara molt activa a la primera part de GCB I.

L'aparició gairebé contemporània dels tres monuments de la identitat política, a més que dinàstica, del casal de Barcelona confirma, per un costat, la hipòtesi metodològica que la fixació de la memòria històrica és conseqüència d'un trencament amb el passat. Per l'altre, revalida l'extrema vinculació, a les terres de la South Frankland, com les anomena Bisson -a Occitània i a Catalunya-, de la història amb el dret, al qual és sovint supeditada $^{60}$.

El trencament amb el passat és fonamental, i a diferents nivells, també polítics, amb repercussions sobre la imatge que els comtes tenen de si

reconstruir el desenvolupament del poder i de les institucions". La situació està progressant, amb noves edicions de reculls documentals, sobretot, però queda encara molt per fer.

${ }^{58}$ ABADAl, Pere el Cerimoniós, pp. 63-80.

${ }^{59}$ JUNYENT, Diplomatari, pp. 304-307.

${ }^{60} \mathrm{Vg}$. BISSON, Unheroed Pasts, p. 282 que cita Bernard GuENÉE, Storia e cultura storica nell'occidente medievale, Bologna, 1991 (ed. or. francès 1980), p. 374. 
mateixos. Perquè, amb l'adquisició del comtat de Provença al 1112 i la recuperació dels de Besalú, al 1111, i de Cerdanya, al 1117; la institució de l'arquebisbat de Tarragona al 1118; la unió amb Aragó, al 1137 i les successives conquestes de Tortosa, al 1148, Lleida i Fraga, al 1149, finalment és possible "répresenter le pouvoir supracomtal en termes dynastiques" ${ }^{61}$. I és exactament en aquest sentit que les Gesta Comitum representen una certa evolució, en direcció de major densitat i complexitat historiogràfica, respecte a una senzilla genealogia -que només explica la transmissió del llinatge i és un element familiar-, o a un neutre llistat de regnants -que representa la continuïtat del govern, i és un element polític ${ }^{62}$.

Això és evident sobretot a començar pels Ramons Berenguers, perquè uneix el concepte de genealogia al de llistat de regnants, i proclama com s'ha sortit de una limitada dimensió familiar del llinatge per donar-li significació política i 'nacional', del moment que aquest llinatge ja no representa i governa només un comtat sinó un conjunt de territoris diferents i, en uns casos, de nova adquisició com a obra de conquesta ${ }^{63}$.

En el cas dels Usatges, el fet mateix de fer remuntar la redacció al temps de Ramon Berenguer I, en lloc dels últims anys del de Ramon Berenguer III i els de Ramon Berenguer IV, crea una dimensió de passat mític que confereix autoritat a l'acció present gràcies a la continuïtat del llinatge ${ }^{64}$

${ }^{61}$ Bisson, L'essor de Catalogne, p. 457.

62 "The regnal list, or king-list, is related to the genealogy, but is nonetheless distict", David N. DumVILLE, Histories and Pseudo-histories of the Insular Middle Ages, Aldershot 1990, XV: "Kingship, genealogies and regnal lists", p. 96, i vg. en general per l'explicitació i anàlisi dels dos conceptes.

${ }^{63}$ Aquest sentiment de diferència havia de ser ja present en el mateix Ramon Berenguer III, així com havia d'exemplificar el seu monument fúnebre (descripció i epitafi a NICOLAU, L'Escola poètica, p. 36) i com és caracteritzat també per altres textos historiogràfics, com ara els annals del ms. BUB 588 , fol. $38 \mathrm{v}$, pels quals, i a diferència d'altres sèries de la família Rivipullense, és el primer regnant, no només català, a gaudir d'una notícia àmplia: "Era ·MCLXVIIII-, anno -MCXXXI. Obiit Raymundus comes Barchinone. Hic Amiliarum et ducatum Provincie, pro uxore sua Dulcia, adquisivit, comitatum Busulnuensem et Ceritaniensem comitatui Barchinone item adiunxit, deffunctis eorundem comitatuum comitibus absque prole. Miles hic strenuissimus, largissimus et amabilis claruit. Maioricas cum Pisanis cepit. Saracenorum triumphator mirabilis fulsit. Tributa ab Ilerda, Tortosa et Valencia accepit. Marte quidem, communi sed optime fine, apud Barchinona dormivit in Domino. In monasterio vero Rivippullensis sepultus quiescit. Huius filius Raymundus Berengarius regnum Aragonensis postea adquisivit, ut infra legitur".

${ }^{64}$ ABADAl, Pere el Cerimoniós, p. 68 parla de "conferir-li un cert caràcter d'antiguitat i de vigència legal". Pels problemes dels orígens i de les etapes de construcció dels Usatges vg., a més de l'edició citada, Joan BASTARDAS, Sobre la problemática dels Usatges de Barcelona, Barcelona 1977 i Frederic UDINA I MARTORELL; Antoni M. UDINA I ABELLÓ, Consideracions a l'entorn del nucli originari dels "Usatici Barchinonae", La formació $i$ expansió del feudalisme català, «Homenatge a Santiago Sobrequès i Vidal» (=«Estudi General» 5-6), Girona 1985-86, pp. 87- 
i que assenyala un moment precís en què s'esdevé una superació i una diferenciació respecte al passat, identificant, així, amb claredat el sentiment d'autonomia del poder que duu a, i permet de, legislar:

Cum Dominus Raimundus Berengarii uetus, comes et marchio Barchinone atque Ispanie subiugator, habuit honorem et uidit et cognouit quod in omnibus causis et negociis ipsius patrie leges gotice non possent obseruari (...) una cum prudentissima coniuge sua Adalmode, constituit et misit usaticos (us. 3).

La definició de la història del llinatge, lligada al sentiment genealògic, i expressada en diferents formes, bé historiogràfiques bé legals, necessitava, també, la clara definició del moment d'inici, de l'origo, i notem que, al segle XII i XIII, no es tracta ni de l'orígen de la terra ni del llinatge, dels quals res sabem respecte a èpoques precedents, sinó del moment de trobada entre la família i la terra. La llegenda que explica l'orígen d'aquest lligam a les Gesta Comitum és elaborada i creada expressament per trobar i fixar l'inici diríem polític, i no mític o biològic, del llinatge - "power and foundation" ${ }^{65}$. Es tracta de la llegenda de Guifré el Pilós que obre les Gesta Comitum, i de la qual parlaré més endavant.

Però, després d'aquest inici molt literari de les Gesta Comitum, no és fins al temps, altre cop exemplar, de Ramon Berenguer I (1035-1076) "qui fuit dictus Vetulus, cui duodecim Hispanie reges tributa persoluisse dicuntur" (GCB I, 6), i sobretot del seu fill Ramon Berenguer II Cap d'Estopes (10761082), que no es noten canvis substancials en una narració que, com hem vist, és poc més d'una genealogia de la família ${ }^{66}$, alhora que del llinatge, encapçalada per un relat mític de fundació. És a aquest comte -del qual es dona una descripció sobretot física, fet gairebé únic, "armis strenuissimus, corpore et forma pulcherrimus"-, i no al seu pare, a qui, en un primer moment,

104. El fet de fer remuntar la redacció dels Usatges a Ramon Berenguer I pot significar la consciència del fet que el nucli primitiu data del regnat d'aquest comte, però assenyala també la solidaritat fundacional i historiogràfica dels quatre Ramons Berenguers, fet que correspon, que sigui de manera confusa, a la percepció de la importància d'aquests comtes, respecte a llurs predecessors, de cara a la estructuració del comtat.

${ }^{65}$ BISSON, Unheroed Pasts, p. 283.

${ }^{66} \mathrm{Vg}$. BISSON, L'essor de Catalogne, p. 462, 1990: 299 i Joan Pau RuBIÉs; Josep Maria SALRACH, Entorn de la mentalitat $i$ la ideologia del bloc de poder feudal a través de la historiografia medieval fins a les quatre grans cròniques, La formació i expansió del feudalisme català, Homenatge a Santiago Sobrequès i Vidal» (= «studi General» 5-6), Girona 1985-86, pp. 467-506, p. 480. 
s'atribueix per error, si de debò ho és, la formulació dels Usatges (GCB I, 7), error immediatament corregit al mateix text.

Tanmateix, la narració, que a partir d'ara es fa sempre més detallada i que no manca de donar-nos la descripció, sobretot de les qualitats morals més que de les físiques, dels monarques, no expressa cap sentiment explícit del llinatge, ni en formula cap plantejament teòric, més enllà del simple fet de narrar-ne l'orígen i la continuïtat, i encara es mou en una dimensió de família, parlant de totes les branques collaterals ${ }^{67}$, tot i que, com veurem, aquesta visió exclusivament familiar s'haurà de matisar. És a partir del relat de la vida de Pere I (1196-1213) que s'aprecia el primer canvi segur en la narració, que es fa més detallada, i en el model polític de reialesa que es presenta, quan es fa referència a la voluntat d'imitar els avantpassats.

Del punt de vista historiogràfic és el Libre dels fets de Jaume I que representa com un trencament d'aquesta construcció de la continuïtat del llinatge, tot i el sentiment que el rei té de la dimensió familiar, al proposar una visió centrada en l'acció del monarca com a nou creador, d'alguna manera deslligat dels avantpassats ${ }^{68}$. Mentre és just a finals del segle XIII, amb Desclot, i amb la segona i tercera redacció de les Gesta Comitum -a les quals els comtes són també, de forma estable i assumida en categories historiogràfiques, reis d'Aragó-, que la importància política de la reialesa i de la seva continuïtat a l'interior del casal de Barcelona, sembla afirmar-se amb més precisió, al costat de l'antiguitat del comtat i del seu sentiment de llinatge.

Però, a part d'aquests comentaris, s'ha de profunditzar més en la valoració de les Gesta Comitum o, més exactament, de la primera, i més antiga, part de la primera redacció. Els historiadors, com hem vist, ja n'han notat el marcat caràcter genealògic, i com comenta Bisson:

It is a singularly coherent set of dinastic genealogies designed to show how the original patrimony of Guifré the Hairy (870-99) was distributed among cadet lines in the tenth century and reconstituted by the great counts of Barcelona in the twelfth ${ }^{69}$.

${ }^{67} \mathrm{~A}$ les Gesta Comitum són resseguides en detall les nissagues comtals que deriven dels comtes de Barcelona, com són els comte d’Urgell, de Besalú i de Cerdanya, però no són mai ni esmentats els altres llinatges comtals que no duien la mateixa sang, com ara els comtes d'Empúries o els de Pallars.

${ }^{68} \mathrm{Vg}$. Stefano Maria Cingolani, Memòria i estratègies comunicatives al 'Libre' del rei Jaume I, «Revista de Catalunya», nova etapa 154, setembre 2000, pp. 111-141 i CINGOLANI, $L a$ memòria dels reis.

${ }^{69}$ Bisson, Unheroed Pasts, p. 299. 
Aquest és el tret fonamental del nucli originari de les Gesta Comitum, que l'apropa de manera determinant, en la seva ideologia i propòsit, al Liber Feudorum maior. Aquesta consideració obliga, tanmateix, a corregir parcialment la visió acabada d'esmentar d'elevar el sentiment de la família pel damunt del llinatge, i permet d'explicar-ne algunes característiques que diferencien les Gesta Comitum d'altra semblant literatura històrico-genealògica.

En primer lloc, la que s'ha de revisar en la seva interpretació és la llegenda fundacional, la de Guifré el Pilós ${ }^{70}$. Hi ha alguns aspectes d'aquesta llegenda que, em sembla, no han estat notats o exactament valorats, havent-se privilegiat el fet de destacar les semblances amb paral-leles llegendes fundacionals, més que evidenciar les diferències. Bournazel caracteritza tres tipus fonamentals de 'llegendes' que defineixen l'orígen de les famílies de la noblesa francesa als segles XI-XII: el tipus que lliga a la sang carolíngia, el que fa remuntar a les nissagues senatorials gal-lo-romanes i el que hi posa un aventurer $^{71}$. Pensem que el de les Gesta Comitum no encaixa amb cap d'aquest models puix que, deixat de banda el segon, té semblances només parcials amb el primer i el tercer cas. Més d'un cop s'ha notat com el fantasiat matrimoni amb la filla del comte de Flandres havia d'aportar sang carolíngia a les venes dels comtes de Barcelona. Tanmateix, la llegenda no té aquest significat: la sang flamenco-carolíngia no és mai esmentada, ni en cap altre text és desenvolupa tal pressuposada relació $^{72}$. Carles, sublimat de diferents

${ }^{70} \mathrm{~A}$ les intervencions fonamentals i tradicionals de Ramon d'ABADAL, Els temps i el regiment del comte Guifred el Pilós, Barcelona 1989 i Miquel COLL I ALENTORN, Llegendari, Barcelona 1993 (Obres IV), pp. 51-135, s'ha d'afegir BISSON, L'essor de Catalogne, BISson, Unheroed Pasts, RuBIÉS; SALRACH, Entorn de la mentalitat, Stefano Maria CingOlani, Modelli storici, tradizioni culturali e identità letteraria nella Catalogna medievale, «Llengua \& Literatura» 5 , (1992-93), pp. 479-494 i, darrerament, Martí AURELL, Les noces del comte. Matrimoni i poder a Catalunya (785-1213), Barcelona 1998 (ed. or. francès 1995), pp. 480-489, el qual, citant DUBY, La société i BOURNAZEL, Mémoire et parenté, insisteix sobre comuns aspectes fundacional; Jaume AURELL, From Genealogies to Chronicles: the Power of the Form in Medieval Catalan Historiography, «Viator», 36 (2005), pp. 235-264; CINGOLANI,La memòria dels reis.

${ }^{71}$ Bournazel, Mémoire et parenté, pp. 117-119.

${ }^{72}$ BISSON, Unheroed Pasts, p. 283 notava com la legitimitat i continuïtat carolíngia no era un tema important per a la escassa historiografia de la South Frankland. La llegenda de Guifré s'ha de confrontar amb la explícitament carolíngia de Bernat de Ribagorça, vg. Ramon d'ABADAL, Dels Visigots als Catalans, 2 vols. Barcelona 1970, pp. 311-329 i BISSON, Unheroed Pasts, pp. 297-299. Només molt més tard, potser al llarg del segle XIV es pensà de reorganitzar la història comtal fent de un Ramon Berenguer el primer comte, pare de Guifré d'Arrià i parent de Carlemany. Difícil imaginar una narració més confusa. Tal com la relata el ms. BC 280, fols. 2 r-v, Carles, un cop conquerida Espanya la reparteix entre uns parents seus: a Ramon Berenguer 
monarques carolingis, és a l'orígen del poder barcelonès i de la seva autonomia, no de la seva sang, i és el temps carolingi -amb sempre menys dependència-, i no pas amb l'adquisició de sang imperial, que serà fixat l'inici de Catalunya, això també en posteriors llegendes, com la d'Otger Cataló.

A més, s'ha de destacar com les llegendes fundacionals catalanes no recerquen la continuïtat sinó, diríem, marcar el moment de la independència de la font del poder $^{73}$. La llegenda, doncs, fixa, de manera històricament confusa i míticament clara, l'anella inicial de l'autoconsciència del llinatge, i identifica els gestos que en creen aquella autònoma existència, existència que narra la històriografia: l'hereditarietat del domini i la necessitat de la seva defensa, sense cap possibilitat d'ajuda reial, això és: naixement i majoria d'edat.

Tampoc, al contrari del que s'ha escrit sovint, no ens equivoquem, Guifré el Pilós no és un aventurer: no ve de fora, del món exterior, per conquerir un nou domini, més o menys legitimat per via matrimonial: Guifré el Pilós és el fill de Guifré d'Arrià, ja comte de Barcelona. Això que comporta, i escenifica la seva aventura, és el passatge de la típica situació carolíngia de la elecció del comte -amb possessió reial de l'honor, atribuït ara a aquest, Guifré, ara a un altre noble, Salomó- a la possessió hereditària del mateix honor $^{74}$ :

Ecce quomodo de potestate regali in manus nostrorum comitum Barchinonensium honor ipse Barchinonensis deuenit $(\mathrm{GCB} I, 5)^{75}$.

Això que importa definir no és tant l'orígen últim del poder, com el seu establiment a mans del casal de Barcelona i la seva continuïtat el sí del

Catalunya, al comte Julià el regne de Granada. La successiva traïció d'aquest últim donarà entrada als sarraïns. Pel que sembla és una tradició tardana i marginal que espera de ser estudiada.

${ }^{73} \mathrm{Vg}$. Cingolani, Modelli storici.

${ }^{74} \mathrm{Per}$ aquesta raó prefereixo parlar de possessió hereditària del títol comtal i no de sobirania, com han fet altres historiadors, per evitar tintes 'nacionalistes' que em semblen fora de lloc per a l'època de què estem parlante.

${ }^{75} \mathrm{De}$ fet, el text en orígen deia cum potestate regoli, en un segon moment, entre 1258 i 1268 , es va corregir en de potestate. Les implicacions d'aquest canvi són prou eloqüents, també per la datació de la llegenda, i les analitzo en detall a les introduccions a les edicions de GCB I i GCB II; de moment vg. Stefano Maria Cingolani, Miti e archetipi. Mito e storia cavalleresca in Catalogna (1040 ca.-1328), Mito e storia nella tradizione cavalleresca (Todi 9-12 ottobre 2005), Spoleto, 2006. 
mateix casal, perquè a les altres llegendes l'heroi és el primer comte, o duc -el fundador-, i no el seu fill. Mentre aquí l'heroi no és Guifré d'Arrià, primer comte elegit i cap del llinatge, sinó el porfirogènit Guifré el Pilós, primer comte hereditari ${ }^{76}$. Així que, al meu entendre, a les Gesta Comitum, a diferència d'altres cròniques genealògiques, això que es vol establir i fixar no és tant l'adveniment del nou poder des de fora -l'aventurer- o justificar-ho per via de llinatge -sang carolíngia o gal·lo-romana-, com, més aviat, certificar la continuïtat hereditària d'aquest poder. L'interès de l'autor del text és en fixar la possessió de l'honor de Barcelona a començar d'un moment determinat en la història -sobretot la genealògica, ja que no hi ha dates-, per veure com, després d'algunes fragmentacions a l'interior de la mateixa família, els dominis s'han anat reunint a la branca principal, amb la notació de les noves adquisicions.

Vistes d'aquesta manera, les Gesta Comitum volen demostrar narrativament això que el Liber Feudorum maior fa de manera documental: el perquè i el quan de l'establiment del dret hereditari a la possessió d'un honor feudal, que sigui el comtat de Besalú o el regne d'Aragó, mostrant així encara una certa dependència de la memòria històrico-genealògica de les exigències legals ${ }^{77}$.

\section{HISTORIOGRAFIA I LEGITIMITAT}

Els dos monuments de la legitimitat del poder del casal de Barcelona mostren la importància determinant que havia assolit al llarg del segle XII la memòria escrita respecte a la oral, també a les terres que envoltaven la

\footnotetext{
${ }^{76} \mathrm{El}$ cas de Guifré és molt semblant al d'altres nissagues reials germàniques, a les quals és el porfirogènit qui dóna el cognomenat a l'estirp, tot i que no sé veure'n lligams directes, que no siguin antropològics, vg. Stefano Maria CingoLANI, Le Storie dei Longobardi. Dalle Origini a Paolo Diacono, Roma, 1995, pp. 91-127.

${ }^{77} \mathrm{Vg}$. BISSON, Unheroed Pasts, p. 282. Al Liber Feudorum maior s'esmenten successivament l'adquisició de la Provença pel matrimoni de Ramon Berenguer III amb Dolça -adquisiuit-, i la seva recuperació de Besalú i Cerdanya -adiunxit- amb la conclusió que: rexit itaque quinque comitatus; la unió amb l'Aragó, pel matrimoni de Ramon Berenguer IV amb Peronella -obtinuiti la confirmació imperial a la Provença -perpetuo adquisiuit-, vg. LFM doc. 901 i 902. La diferència de percepció, respecte a la formació del seu domini, que hi ha entre pare i fill, resulta evident en els testaments: Ramon Berenguer III torna a esmentar tots i cadascú dels dominis que li pertanyen i que són de nova adquisició (UDINA I ABELLÓ, Els testaments, pp. 101-102), mentre el fill parla senzillament de honorem (...) Barchinona (UDINA I ABELLÓ, Els testaments, p. 104).
} 
mediterrània, terres més romanitzades, respecte a les del nord, i que més havien mantingut pràctiques notarials ${ }^{78}$.

El text historiogràfic s'encarrega de transmetre pel futur la memòria, en forma escrita, memòria a la qual acudir en cerca de proves i de drets davant d'alguna contesa política o administrativa. El passatge de la memòria oral a la escrita, tot i no eliminar el recurs al record o a la tradició ${ }^{79}$, privilegia la producció de proves escrites, que es podien extreure ara de la documentació ara de les cròniques. El testimoni de les cròniques, que a la seva manera desenrotllaven l'aspecte mític de la prova amb relats fantàstics sobre els orígens, tenia la seva importància a l'hora d'aclarir drets feudals. És el cas, per exemple, de quan Eduard I d'Anglaterra, al 1291, va ordenar una enquesta que demostrés els seus drets a la corona d'Escòcia recorrent també al testimoni de les cròniques ${ }^{80}$. El mateix Pere II, a les Corts de Barcelona de 1283, estableix, en relació al pagament del bovatge, que serà pagat només per qui ja antigament tenia l'obligació de pagar-lo, i pel que fa a les proves que corroborin l'obligació, o l'exempció, del pagament es diu:

V. Ultra vero terminum predictum non possimus probare aliquid de forma nec locis non probatis, sic tamen quod dictum bovaticum probemus, sicut facta antiquitus possunt et debent probari, scilicet per instrumenta, libros et scripturas alias et per famam (Cortes, p. 143).

La historiografia s'encarrega, així, de manera oficial o, millor, com apunta Guenée ${ }^{81}$ oficiosa, de transmetre relats, que a vegades arrenquen directament de la propaganda, amb la finalitat de defensar, en un possible futur, els drets d'una o altra monarquia ${ }^{82}$. La importància de la prova escrita, bé document bé crònica, és mostrada pel relleu que adquireix ara la recerca

${ }^{78} \mathrm{Vg}$. M.T. Clanchy, From Memory to Written Record, England 1066-1307, 2nd ed., Oxford, 1993.

${ }^{79}$ Per exemple, en la gran enquesta duta a terme pel rei d'Anglaterra Eduard I, a final del segle XIII, sobre els drets feudals de la noblesa, l'anomenada enquesta del quo warranto, l'Earl de Warenne va produir com a prova dels seus drets ancestrals una espasa que era en possessió de la seva família des dels temps de la conquesta de Guillem I, prova que tenia la seva força en la continuïtat de la tradició familiar i el significat mític i simbòlic de la mateixa espasa. Per aquest $\mathrm{i}$ altres casos vg. ClanCHY, From Memory, pp. 35-40.

${ }^{80}$ ClanCHY, From Memory, pp. 40-43 i 101.

${ }^{81}$ GUENÉE, Storia e cultura storica, pp. 405-407.

${ }^{82} \mathrm{Vg}$. GUENÉE, Storia e cultura storica, pp. 399-429. 
de fonts que mereixin confiança a causa de la seva autoritat, ara la continuada i renovada creació de falsos de tot gènere per tal de fonamentar la reclamació o la defensa d'uns drets ${ }^{83}$. Falsos que segueixen l'exemple, tot i no tenir-ne la importància, de la famosíssima donationem Constantini que, tot i ser molt més antiga, determinà gran part de la vida política medieval i que Lorenzo Valla va demonstrar falsa al $1440^{84}$.

La invenció de relats i llegendes, o la seva inserció, en els llibres de història forma part, doncs, d'una pràctica antiga, força comuna i absolutament acceptada, i el caràcter mític i llegendari dels relats els fa especialment valuosos pel seu significat paradigmàtic i perquè un dret adquireix tant més força i pes, com més enrere en el temps és fonamentat. La historiografia s'encarrega, també, de formar la memòria del futur, més que de difondre la propaganda del present.

Tot i així, s'ha de destacar que aquesta memòria, i legitimitat, pel futur pot ésser fondada sobre la 'història' o sobre la 'llegenda', i Desclot, més radicalment encara a la segona redacció de la seva crònica, seguirà en més d'un cas justament la llegenda. La legitimitat de la 'història', aquella de la qual parlen Eduard I i Pere II, és aquella que, per exemple, es va forjar en el Doomesday Book, el 'llibre del dia del destí', de la cancelleria anglesa de Guillem I. Havia de fer un cens de la propietat agrícola a l'Anglaterra de després de la conquesta i es va transformar en un llibre simbòlic, com mostra el seu mateix nom ${ }^{85}$.

\section{RETÓRICA CURIAL I TEORIA POLÍTICA}

Una semblant voluntat de fixació de la legitimitat la devem, com ja he dit més amunt, al comte-rei Alfons, I com a comte de Barcelona, II com a rei d'Aragó, i primer rei de la nova confederació. És al seu regnat, tot i que és impossible decidir si és un acte de la seva influència directa, que devem la redacció del fonament de la legitimitat històrico-dinàstica del llinatge i del seu dret a governar, tal com ho estableixen les Gesta Comitum Barcinonensium,

\footnotetext{
${ }^{83} \mathrm{Vg}$. GuENÉE, Storia e cultura storica, pp. 159-184.

${ }^{84} \mathrm{Vg}$. Lorenzo Valla, La falsa donazione di Costantino, introduzione, traduzione e note di Olga PUGLIESE, Milano, 1994

${ }^{85} \mathrm{Vg}$. Clanchy, From Memory, pp. 32-35.
} 
i, pel que he anat apuntant, també és al seu regnat que devem l'elaboració de nous conceptes de reialesa, tot i que aquesta es fonamenta en les elaboracions de la cúria 'romanitzant' del seu pare. Tanmateix, la licitud, diríem feudal, al govern, la que ve d'un acte mític i del passatge de pare en fill de les terres amb les noves incorporacions, és acompanyada per la paral·lela licitud, ara diríem burocràtica, al mateix govern amb la redacció del Liber Feudorum maior, cartulari en què es recull tota la documentació que legitima el govern i la possessió de tots els honores que pertanyen al casal de Barcelona ${ }^{86}$. pròleg $^{87}$ :

Extremadament significatiu d'un embrió de teoria política n'és el

Qui, enim, exaltationem persone vestre diligunt et terrarum vobis a Deo comissarum profectus affectant dilatari, suavissima debent iocunditate gaudere, cum excellentissimam vestram videant personam ad ea mentem dirigere, que ad honorem Dei et utilitatem regni vestri dinoscuntur pertinere. Inter ceteras, namque, virtutum copias, que vos inter alios decorant principes, illud in vobis video completum quod legitur: nihil est quod clariore luce prefulgeat quam recta fides in principe. Huius, igitur, fidei rectitudine ductus, sepenumero inter alia grandia et ardua, divina instillante gratia, viva expressistis voce, vos habere votum et desiderium ut omnia instrumenta propria et inter vos vestrosque antecessores ac homines vestros confecta, et in ordinatione confussa, sub uno redigerentur volumine, tum propter subiectorum, scilicet, utilitate, ut, his instrumentis ad memoriam revocatis, unusquisque ius suum sortiatur, tum propter eternam magnarum rerum memoriam, ne inter vos et homines vestros, forte oblivioni occasione, aliqua questio vel discordia posset oriri.

La simbologia del dret feudal és un tema que s'hauria d'estudiar, almenys com ha anat variant i com s'ha anat transformant en una concepció més moderna d'arxiu. I que aquest llibre revesteix un significat també simbòlic, a més que pràctic, és demostrat per les nombroses miniatures que el decoren i que il·lustren figurativament el poder dels comtes i el seu legítim

\footnotetext{
${ }^{86} \mathrm{Vg}$. per més exemples i una interpretació de conjunt Robert I. BURNS, S.J., Societat $i$ documentació en el regne croat de València (Diplomatarium I: Introducció), València, 1988 (ed. or. anglès 1985), pp. 29-41.

${ }^{87}$ S'hauria d'estudiar juntament al canvi radical portat per Alfons I al concepte de Pau i Treva (vg. GonZALVO I BoU, La Pau i Treva, pp. 50-62), amb totes les conseqüències que té en la imatge del rei i de la seva missió, a més que de la seva relació amb el regne.
} 
eixamplament ${ }^{88}$. Però, ni Pere I ni Jaume I segueixen amb la mateixa concepció pública del Liber Feudorum, i no hi afegeixen els documents justificatius dels honors per ells adquirits i pels quals podien reivindicar la possessió. Posseïm un document del rei Jaume I que és extremadament interessant de la seva concepció, que es podria definir com a privada $\mathrm{i}$ personal -en línia amb tota la seva acció de govern. El 20.5.1269, des de Huesca, escriu a la abadessa de Sixena, monestir on a l'època havia decidit fer-se enterrar, per dir-li que:

\begin{abstract}
Noveritis quod mittimus fidelem scriptorem nostrum Michaelem Violeta ad vos pro aliquibus instrumentis nostris, que tangunt factum regis Navarre, quare mandamus vobis quod tradatis eidem clavem arche nostre, ubi sunt instrumenta nostra, et permitatis ipsum extrahere inde omnia instrumenta predicta et ducere ipsa nobis ${ }^{89}$.
\end{abstract}

Si no interpreto malament, el rei Jaume, en lloc de seguir afegint els fonaments legals dels nous drets i de les noves possessions al llibre del llinatge, pensava guardar el seu propi 'llibre del destí' al seu mausoleu ${ }^{90}$.

La retòrica de Ramon de Caldas, responsable del Liber Feudorum Maior, és més elaborada i més cortesana que la de l'anònim de les Gesta Comitum, en aquest cas molt possiblement un monjo de Ripoll, i és reveladora d'unes concepcions del poder més 'modernes' i d'influència romana, respecte a les encara en bona mesura feudals de les Gesta. 'Modernitat' que mostren, també, les constitucions de Pau i Treva de Fondarella de $1173^{91}$. És que una notable correspondència amb la retòrica, i les idees, de Ramon de Caldes la podem justament retrobar en l'anònim redactor de les constitucions de Pau i Treva de Fondarella de 1173:

Divinarum et humanarum rerum tuicio ad neminem magis quam ad principem pertinet, nichilque tam proprium debet esse boni ac recti

\footnotetext{
${ }^{88} \mathrm{Vg}$. per les miniatures José Enrique RuIz DomÈnEC, A propósito de Alfonso, rey de Aragón, conde de Barcelona y marqués de Provenza, Barcelona, 1996, pp. 118-123 i en general Bonifacio PALACIOS MARTíN, Imágenes y símbolos del poder real en la Corona de Aragón, «XV Congreso de Historia de la Corona de Aragon»: El poder real en la Corona de Aragon (siglos XIV-XVI), Zaragoza, 1996, I, $1^{\circ}$, pp. 189-229.

${ }^{89}$ Ambrosio HUICI, Colección diplomatica de Jaime I, el Conquistador, 3 vols, Valencia 1916-22, doc. 1322.

${ }^{90} \mathrm{Vg}$. BURNS, Societat i documentació, pp. 33-36.

${ }^{91}$ Bisson parla, per a les GCB, de "vision traditionnelle de la société" (1984: 464).
} 
principis quam iniurias propulsare, bella sedare, pacem stabilire et informare, et informatam subditis conservandam tradere, ut de eo non incongrue dici et predicare possit quod a principe regum dictum est, per me reges regnant et potentes scribunt iusticiam ${ }^{92}$.

No és aquest el lloc per dur a terme un estudi sobre la retòrica de la cancelleria catalano-aragonesa al segle XII, però no es pot deixar de notar com l'estil de la cúria alfonsina és la natural evolució del de la cúria de Ramon Berenguer IV: aquesta ja emergeix tímidament en els articles dels Usatges que a la seva època remunten, i és claríssima a l'epitafi del comte-rei, que, segon diuen Flórez i Bofarull, era enterrat al sepulcre del comte:

\begin{abstract}
Hic certe rex pacis, princeps justitiae Dux veritatis et aequitatis, armiger intemerate fidei christianae, contra Sarracenos et infideles debelator fortis, cujus sagita numquam abiit retrorsum, nec declinavit clipeus ejus in bello, et ejus numquam est aversa hasta. Incliti Christianorum plebis flete, quoniam cecidit dux vester. (...) Plora igitur plora, deducant occuli tui lacrimas per diem et noctem quoniam defecit anchora spei tuae. (...) Heu Serenissime Rex et Victoriosissime Princeps Raymunde Berengarii nostrae sustentationis baculum: Ubi es? Ubi cubas? (...) plaudeat hodie plebs Cathalana et Aragonensis; undique jucundetur christiana concio: hodie certe iste Victoriosissimus Princeps et Dominus Raymundus Berengari obtinuit quod tanto tempore estuabat desiderio: hodie devictis hostibus securum obtinuit triunfum, certe omnibus expletis laboribus requiem possidet sine fine ${ }^{93}$.
\end{abstract}

És gairebé impensable que els cancellers d'Alfons I, Ramon de Caldes i l'anònim redactor de les costicions de Pau i Treva, o el monjo de Ripoll duguessin a terme les seves empreses, literàries i ideològiques, sense una disposició reial. Tot i així, la falta de qualsevol pròleg i dedicatòria a les Gesta Comitum, i la retòrica romana del Liber Feudorum maior i de les constitucions, fan impossible saber el nivell de vinculació reial, no tant, com he dit, en la impulsió dels projectes, que és prou evident -les Gesta parlen de nostrorum comitum, les constitucions de terre mee i de meum amorem-, com, més aviat, en les característiques dels seus acabaments retòrics i ideològics,

\footnotetext{
${ }^{92}$ Constitucions, p. 77.
}

${ }^{93}$ FlóReZ, España sagrada, pp. 466-470, també a Próspero de BOFARULl Y MASCARó, Los Condes de Barcelona vindicados, 2 vols., Barcelona, 1836, reimpresió anastàtica Barcelona, 1988, vol. II, pp. 201-205. 
tant que és impossible saber qual de les dues empreses era més propera a les intencions del rei Alfons I.

Aquest grup de textos representa diferents aspectes de la nova ideologia monàrquica, i respon a la seva representació en contextos socials i culturals diferents, malgrat la comuna condició clerical dels autors. Però, no sabem en quina mesura es correspon, bé en termes polítics bé culturals, a la voluntat, als interessos i als gustos del mateix comte-rei, rei pel qual la crítica ha sempre destacat la dificultat d'una exacta aproximació crítica. El problema és copsar, es podria dir, bé en quina manera aquests textos es corresponen amb un impuls reial conscient, bé, al contrari, són una superposició externa o, com a mínim, força llunyana.

En efecte, la personalitat 'cultural' del rei, pel què en podem entendre, no sembla dirigir-se ni al llatí ni a la història, tot i la seva necessària atenció institucional a la governabilitat i transformació dels seus estats. En primer lloc, s'ha de notar com, justament amb el regnat d'Alfons I, s'interromp la secular tradició de poesia encomiàstica llatina: després del planctus en honor de Ramon Berenguer IV, Mentem meam ledit dolor, hem d'esperar més de 100 anys perquè la costum es torni a recollir amb els poemes en honor de Pere II i de Jaume II $^{94}$.

També ambigua és la situació de les Gesta Comitum: tot i la falta de declaracions explícites, és difícil no interpretar-les com a una comissió reial, també tenint en compte la condició de pantheon, i reserva de memòria, que caracteritzava el monestir de Ripoll. Malgrat això, però, no sembla haver-hi hagut una directa i constant atenció reial a la continuació del record en la crònica -pensem que a partir d'Alfons I els comtes-reis no seran enterrats a Ripoll. Malgrat que el segon redactor de les Gesta escriu que "de uita et actibus" del rei "hucusque scripta sufficiant" (GCB I, 15), la importància del rei Alfons, i els seus èxits, no emergeixen pas d'aquest breu, insuficient $\mathrm{i}$ esmunyedís relat. Ben al contrari, a les Gesta nomès apareixen de manera esporàdica les problemàtiques relacions amb la Provença i el Llenguadoc, i la concisa narració es concentra en un perifèric relat dels enfrontaments del 1191 amb Castella i de la temptativa, al 1195, de reorganitzar les forces peninsulars després de la derrota d'Alarcos.

${ }^{94} \mathrm{Vg}$. NiCOLAU, L'Escola poètica, p. 40, per Pere II, pel poema sobre Jaume II, inèdit fins ara, vg. CingOLANI, Historiografia, propaganda, Apèndix 5. 
Tampoc el rei es va cuidar, ni els monjos, de la disseminació de les Gesta pel territori. La primera redacció, GCB I, és continuada per diferents redactors de manera sempre breu i sintètica fins als últims anys del regnat de Jaume I, i no és fins aquest moment que no surt del monestir ${ }^{95}$. El seu cas és molt diferent, per exemple, del de l'Anglo-Saxon Chronicle, puix que el rei Alfred, a més de ordenar-ne la redacció, en va fer difondre de seguida diferents exemplars a diversos monestirs perquè en guardessin memòria i la continuessin, fet que porta a que se n'han transmès redaccions radicalment diferents a partir del moments de la dispersió dels exemplars. Com també és diferent el cas de les sèries d'annals originades a Ripoll ${ }^{96}$, i d'aquí escampades a altres fundacions monàstiques, si és encertada la reconstrucció de Coll $\mathrm{i}$ Alentorn $^{97}$.

Les Gesta Comitum no surten fins al final del regnat de Jaume I, quan la versió llatina intermèdia, una perduda revisió de GCB I, és traduïda al català, però no pas continuada, potser perquè això que interessava, altre cop, era fixar el passat no pas continuar en el present. Només la necessitat de divulgació prop un públic llec en justifica la versió al català, i la motiva, possiblement, com a funcional per tal d'acompanyar unes compilacions d'Usatges i privilegis de la ciutat, els quals transmeten també la anomenada Cronica comunia, que no és altra cosa que un recull d'annals ${ }^{98}$. És a dir que la historiografia, el record del passat, encara al segle XIII segueix en molts casos supeditat al dret i no gaudeix d'autonomia.

És que allò que li interessava a Alfons I -com possiblement a Pere I i a Jaume I durant el regnat dels quals hi ha un col-lapse absolut de la retòrica àulica de la cúria alfonsina-, era la poesia trobadoresca, una elecció 'cultural' de signe radicalment diferent i oposat, i de la qual, al meu entendre, se n'ha de revisar l'importància, en positiu i en negatiu. És una elecció que ocorre en un moment determinant del procés cultural europeu, el moment del passatge

${ }^{95} \mathrm{Vg}$. Cingolani, La memòria dels reis, i Stefano Maria Cingolani, De la història privada a la història pública, "Butlletí de la Societat Catalana d'Estudis Històrics», en premsa.

${ }^{96} \mathrm{O}$ els Usatges pels quals afirma orgullosament el primer autor de les Gesta que: "quorum exemplaria per uniuersam regionem nostram hactenus leguntur et obseruantur" (GCB I, 7).

${ }^{97}$ Coll, Historiografia, pp. 27-31

${ }^{98}$ Es tracta del Llibre de privilegis de Ramon Ferrer i del Llibre Verd, conservats a l'Arxiu d'Història de la Ciutat de Barcelona amb els números 1G-9 i 1G-10. El tema és estudiat en profunditat a CingOlani, La memòria dels reis, CINGOLANI, De la història privada, i a l'edició de GCB II, que tinc en preparació 
definitiu del monestir a la església catedral, i secundàriament a la cort; doncs, a les ciutats, com a pol d'atracció i de producció intel·lectual, passatge que requereix unes estructures político-socials que encara no existien a Catalunya, i la, almenys indirecta, protecció, o impuls, reial.

Mentre l'elecció del rei Alfons I per unes formes 'culturals' que no són, a l'època, gaire cosa més que un refinat entreteniment aristocràtic, tindrà conseqüències determinants, i no totalment positives, diria, de cara a la configuració cultural de la Corona d'Aragó, que tardarà molt, quelcom més que un segle, a sortir d'aquella exclusiva, i reductiva, aposta per la lírica en vulgar, desdenyant, fins els temps de Jaume II, qualsevol mena d'interès i protecció per la cultura més elevada, sàvia, i, per tant, elitista, en llengua llatina. Aquesta tendència deixarà un buit enorme en l'estructura cultural, i, en última instància, literària, del Principat, buit que costarà molta feina i molt de temps tornar a omplir, almenys parcialment.

És aquest un notable exemple de l'ambivalència de la personalitat del rei, modernitzador dels seus reialmes ${ }^{99}$, en contacte directe amb intel·lectuals com Ramon de Caldes o uns anònims monjos de Ripoll -dels quals no s'ha de subestimar la formació clàssica-, directe o indirecte impulsor de la creació de noves biblioteques catedralícies, com la de Tortosa, i, tanmateix, dedicat al cultiu d'una literatura, que sí és moderna, però és també fàcil -que li portà el sobrenom de 'el Trobador'-, literatura aristocràtica i feudal -tot el contrari dels 'seriosos' reis Capets contemporanis. Literatura de la qual, tanmateix, s'ha de destacar la importància política ${ }^{100}$, fet que potser en justifica el cultiu i la protecció reial, donant pistes també respecte a les seves necessitats i prioritats polítiques: el control de la noblesa.

Potser hauríem de veure la pràctica de la poesia trobadoresca com l'altra cara, l'entretinguda i acceptable, de l'afirmació de la Pau i Treva reial. Una manera ambigua, per part del rei, de posar-se ara, amb la poesia, al mateix nivell dels seus barons -és el comte, noble entre nobles-, ara, amb la Pau del rei, és el príncep per control-lar-los -tanmateix, sense gaire resultats definitius-, i sempre de manera personal, com manifesten les constitucions de Fonderella: Alfonso.

${ }^{99} \mathrm{Vg}$. BISson, L'essor de Catalogne i, amb certes cauteles, RuIZ DoMÈnEC, A propósito de

${ }^{100} \mathrm{Vg}$. Anton M.EsPadeler, La Catalogna dei Re, Piero BoITAnI; Mario ManCINI; Alberto VARVARO (eds.), Lo spazio letterario del Medioevo: 2. Il Medioevo volgare, Roma, 2001, pp. 873-933, p. 883. 
Ego Ildfonsus (...) iuro per Deum (...) quod predictam pacem et treugam firmiter tenebo et observabo, et teneri et observari ab omnibus omni modo volo atque precipio. Quam si quis infringerit, non habebit meum amorem vel sub acuydamento meo erit quousque supradicto modo restituat quod rapuerit vel infringerit ${ }^{101}$ (Constitucions, p. 81-82).

O com escriu ell mateix en un partimen amb Guiraut de Bornelh ${ }^{102}$ :

Giraut, e non esta genseis, si.l rics sap onrar ni temer sidons, e 1 cor ab lo poder l'ajosta?

D'aquesta manera, doncs, nombrosos indicis assenyalen el regnat d'Alfons I com un moment determinant d'evolució i innovació en la reflecció sobre poder, llinatge, noblesa, memòria i història, deixant-nos fins i tot la raonable sospita que darrere d'alguna d'aquestes novetats hi hem de veure, directa o indirectament, la mateixa persona del rei. Malgrat això, però, l'escassedat de la documentació, la falta d'investigació, les dificultats en atènyer una percepció més exacta de la personalitat i de l'obra d'Alfons I, no permeten de perfilar amb més exactitud aquestes hipòtesis, ni de precisar els punts d'intersecció entre les diferents liníes evolutives, i ens hem de satisfer, almenys de moment, amb poder destacar una zona, el regnat d'Alfons I, de la qual el llegat dels seus avantpassats en surt profundament, però no totalment, transformat, sense que sigui possible copsar exactament els punts d'inflecció, ni els moments i els responsables dels intercanvis.

\footnotetext{
${ }^{101}$ Constitucions, p. 81-82.

${ }^{102}$ Martí de RIQUER, Los Trovadores, 3 vols., Barcelona, 1975, vol. I, p. 572, vv. 25-28.
} 